Research papers

\title{
Complex conductivity of oil-contaminated clayey soils
}

\author{
Yaping Deng ${ }^{\mathrm{a}, \mathrm{b}}$, Xiaoqing Shi ${ }^{\mathrm{a}, *}$, André Revil ${ }^{\mathrm{b}, *}$, Jichun $\mathrm{Wu}^{\mathrm{a}}, \mathrm{A}$. Ghorbani ${ }^{\mathrm{c}}$ \\ ${ }^{a}$ Key Laboratory of Surficial Geochemistry of Ministry of Education, School of Earth Sciences and Engineering, Nanjing University, Nanjing 210023, China \\ ${ }^{\mathrm{b}}$ Univ. Grenoble Alpes, Univ. Savoie Mont Blanc, CNRS, IRD, IFSTTAR, ISTerre, 38000 Grenoble, France \\ ${ }^{\mathrm{c}}$ Department of Mining and Metallurgical Engineering, Yazd University, Iran
}

\section{A R T I C L E I N F O}

This manuscript was handled by P. Kitanidis, Editor-in-Chief, with the assistance of Jian Luo, Associate Editor

Keywords:

Spectral induced polarization

Oil contamination

Saturation exponent

Quadrature conductivity exponent

Geophysics

\begin{abstract}
A B S T R A C T
Spectral induced polarization (SIP) is considered as a promising tool in environmental investigations. However, few works have done regarding the electrical signature of oil contamination of clayey soils upon induced polarization. Laboratory column experiments plus one sandbox experiment are conducted in this study to investigate the performances of the SIP method in oil-contaminated soils. First, a total of 12 soils are investigated to reveal the influences of water and soil properties on the saturation dependence of the complex conductivity below $100 \mathrm{~Hz}$. Results show that the magnitude of the complex conductivity consistently decreases with decreasing water saturation for all soils samples. The saturation $n$ and quadrature conductivity $p$ exponents tend to increase slightly with increasing water salinity when using a linear conductivity model. The saturation exponent increases marginally with the cation exchange capacity (CEC) and the specific surface area $\left(S_{s p}\right)$ while the quadrature conductivity exponent exhibits a relatively stronger dependence on both CEC and $S_{s p}$. For the low CEC soil samples (normally $\leq 10 \mathrm{meq} / 100 \mathrm{~g}$ ), the quadrature conductivity exponent $p$ correlates well with the saturation exponent $n$ using the relationship $p=n-1$. SIP method is further applied in a sandbox experiment to estimate the saturation distribution and total volume of the oil. Results demonstrate that the SIP method has a great potential for mapping the organic contaminant plume and quantifying the oil volume.
\end{abstract}

\section{Introduction}

Non-intrusive geophysical techniques, especially geoelectrical methods are gaining popularity in environmental problems (e.g., Rubin and Hubbard, 2005; Atekwana and Atekwana, 2010; Mao et al., 2015). Among them, spectral induced polarization (SIP), also called complex conductivity, has emerged as a promising tool for the identification of contamination due to its sensitivity to the chemistry of pore water, solid-fluid interfaces and fluid content (e.g., Vaudelet et al., 2011; Kemna, 2012; Revil, 2013b). Complex conductivity comprises an inphase component characterizing the transport of ions by electromigration due to an external electric field. In turn this in-phase component comprises a conduction in the electrical double layer coating the surface of the grains and a bulk conductivity associated with the conduction in the pore network. The imaginary part (or quadrature conductivity) describes the ability of the porous material to store reversibly electrical charges under the same applied (external) electrical field. It comprises typically two contributions: a membrane polarization component and an electrical double layer polarization component (Vinegar and Waxman, 1984).
In the last few decades, the SIP method has been increasingly applied in hydrogeological studies, to test its sensitivity to the permeability (Binley et al., 2005; Revil and Florsch, 2010), the pore/grain size distribution (Koch et al., 2011; Revil et al., 2012b), the chemical composition of the pore fluid (Lesmes and Frye, 2001), the wettability of the oil (Revil et al., 2011), the water content (Ulrich and Slater, 2004; Breede and Kemna, 2012) and microbial processes (Revil et al., 2012a; Heenan et al., 2013; Atekwana and Aal, 2015). In addition to the successful applications of the SIP technique in these aspects, it also plays a role in characterizing organic contamination in soil and groundwater systems (Börner et al., 1993; Vanhala, 1997).

Although the SIP technique shows great potentials in the detection of oil contamination, previous studies suggested inconsistent responses of SIP in the presence of oil. A decrease in the magnitude of both inphase and quadrature conductivities in porous sand and sandstones with increasing oil saturation was shown by Börner et al. (1993) and Schmutz et al. (2010), while Vanhala (1997) and Schwartz et al. (2012) reported that the in-phase conductivity increased with the addition of the oil to the clean samples. This inconsistence can be explained by the wettability of oil with respect to the solid phase (Revil et al., 2011;

\footnotetext{
* Corresponding authors.

E-mail addresses: dg1529039@smail.nju.edu.cn (Y. Deng), shixq@nju.edu.cn (X. Shi), andre.revil@univ-smb.fr (A. Revil), jcwu@nju.edu.cn (J. Wu), ah.ghorbani@yahoo.fr (A. Ghorbani).
} 
Table 1

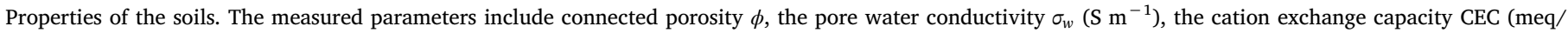
$100 \mathrm{~g})$, the specific surface area $S_{s p}\left(\mathrm{~m}^{2} \mathrm{~g}^{-1}\right)$, the formation factor $F$ and the surface conductivity $\sigma_{s}\left(\mathrm{~S} \mathrm{~m} \mathrm{~m}^{-1}\right)$.

\begin{tabular}{|c|c|c|c|c|c|c|c|c|}
\hline Soil ID & Type & Natural/Artificial & $\phi$ & $\sigma_{w}\left(\mathrm{~S} \mathrm{~m}^{-1}\right)$ & CEC (meq/100 g) & $S_{s p}\left(\mathrm{~m}^{2} \mathrm{~g}^{-1}\right)$ & $F$ & $\sigma_{S}\left(\mathrm{~S} \mathrm{~m}^{-1}\right)$ \\
\hline $\mathrm{AB}$ & Fine sand & Natural & 0.34 & 0.0056 & $7.1^{\mathrm{a}}$ & $6.52^{\mathrm{a}}$ & $6.3^{\mathrm{a}}$ & $0.23^{\mathrm{a}}$ \\
\hline $\mathrm{AX}$ & Fine sand & Natural & 0.35 & 0.0056 & $7.5^{\mathrm{a}}$ & $4.91^{\mathrm{a}}$ & $10.98^{\mathrm{a}}$ & $0.24^{\mathrm{a}}$ \\
\hline $\mathrm{AY}$ & Fine sand & Natural & 0.36 & 0.0058 & $1.9^{\mathrm{a}}$ & $2.18^{\mathrm{a}}$ & $10.18^{\mathrm{a}}$ & $0.19^{\mathrm{a}}$ \\
\hline BL & Fine sand & Natural & 0.45 & 0.0057 & $3.6^{\mathrm{a}}$ & $7.0^{\mathrm{a}}$ & $6.32^{\mathrm{a}}$ & $0.36^{\mathrm{a}}$ \\
\hline $\mathrm{BF}$ & Sandy clay & Natural & 0.55 & 0.0055 & $16.8^{\mathrm{a}}$ & $7.9^{\mathrm{a}}$ & $6.3^{\mathrm{a}}$ & $0.34^{\mathrm{a}}$ \\
\hline BJ & Sandy clay & Natural & 0.44 & 0.0054 & $3.6^{\mathrm{a}}$ & $9.5^{\mathrm{a}}$ & $7.28^{\mathrm{a}}$ & $0.27^{\mathrm{a}}$ \\
\hline$C D$ & Sandy clay & Natural & 0.46 & 0.0056 & $6.5^{\mathrm{a}}$ & $8.7^{\mathrm{a}}$ & $9.1^{\mathrm{a}}$ & $0.45^{\mathrm{a}}$ \\
\hline BG & Clay & Natural & 0.71 & 0.0060 & $14.2^{\mathrm{a}}$ & $14.6^{\mathrm{a}}$ & $5.4^{\mathrm{a}}$ & $0.39^{\mathrm{a}}$ \\
\hline AR & Sandy clay & Natural & 0.42 & 0.1 & 7.6 & - & 4.35 & 0.01 \\
\hline $\mathrm{RP}$ & Clay & Natural & 0.57 & 0.0056 & 2.6 & 14.7 & - & - \\
\hline PS & Pure sand & Artificial & 0.35 & 0.0055 & - & - & - & - \\
\hline SS5\% & $95 \%$ clean sand $+5 \%$ smectite & Artificial & 0.50 & 0.0055 & - & - & - & - \\
\hline
\end{tabular}

a Data from Revil et al. (2017).

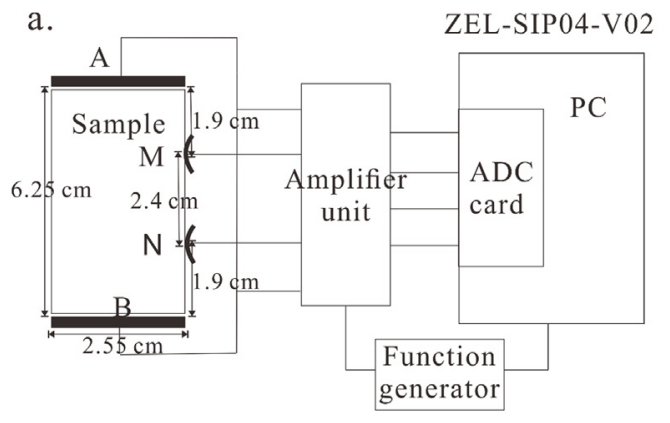

b.

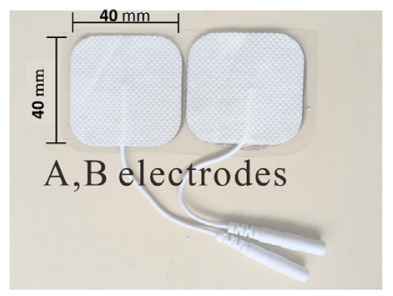

c.

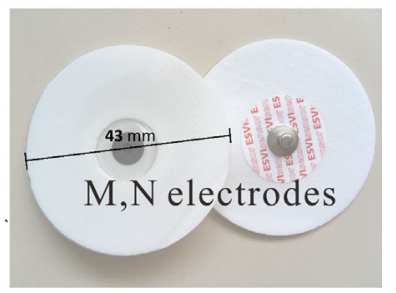

Fig. 1. Sketch of the experimental setup for all spectral induced polarization (SIP) measurements. (a) Illustration of the electrodes position and SIP instrumentation. (b) The current electrodes A, B. The electrodes are made of conductive carbon film and biocompatible hydrogel widely used in medical field. (c) The voltage electrodes $\mathrm{M}, \mathrm{N}$, consisting of $\mathrm{Ag} / \mathrm{AgCl}$ disk and hydrogel. The advantage of medical electrodes used in this study over metallic electrodes is that the former has lower noise signal transfer and minimized spurious polarization effects.

Schwartz and Furman, 2012). The polar organic compounds contained in the wetting oil can replace the inorganic ions on mineral surfaces, which causes the increase in the conductivity of pore water (e.g., Vanhala, 1997; Schwartz et al., 2012). In this work, we focus on the influence of non-conductive oil on the SIP signature of soils. Thus, in order to isolate from the complex exchange processes between the polar organic compounds and inorganic ions absorbed to the mineral surfaces, the nonpolar hydrocarbon (pure decane) is chosen as the organic contaminant in this study.

Previous studies have demonstrated the saturation dependence of the in-phase (Archie, 1942; Waxman and Smits, 1968) and quadrature conductivities (Vinegar and Waxman, 1984; Maineult et al., 2017), especially for sedimentary rocks. The second Archie's law has been used for years to quantify the hydrocarbon amount. According to Archie (1942), it was given by:

$S_{w}=\left(R_{o} / R\right)^{-n}$

where $S_{w}$ is water saturation, $R_{o}$ is the resistivity of fully water
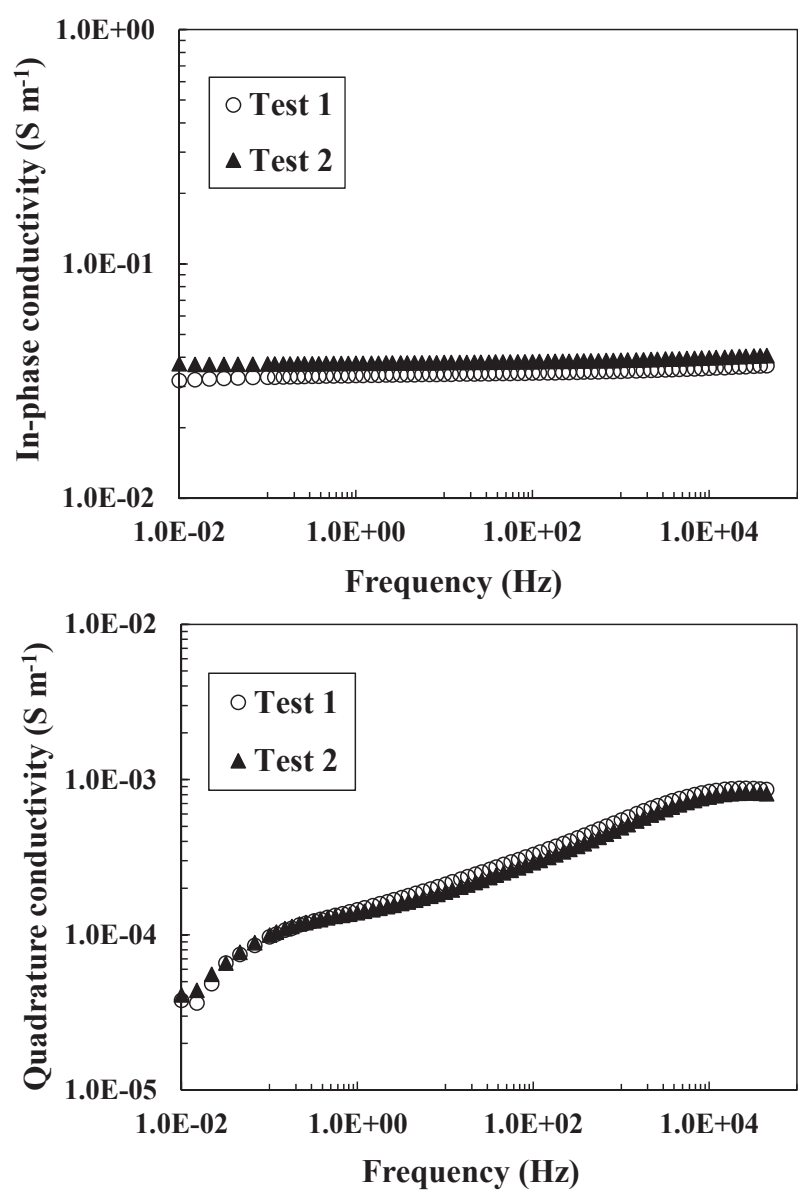

Fig. 2. The measured in-phase $\left(\sigma^{\prime}\right)$ and quadrature $\left(\sigma^{\prime \prime}\right)$ conductivities of two separate samples (labeled as Test 1 and Test 2) with the same soil material (sample $\mathrm{AX}$ ) as a function of frequency. Both samples were measured under fully water saturated condition with same pore water conductivity $(0.0056 \mathrm{~S}$ $\left.\mathrm{m}^{-1}\right)$ and room temperature $\left(19^{\circ} \mathrm{C}\right)$.

saturated sample, $R$ is the real resistivity, $n$ is the saturation exponent. It is extremely common to assume $n \approx 2$ for most rocks and porous media in laboratory and field investigations (Hearst et al., 2000; Chambers et al., 2004; Breen et al., 2012). The problem is that $n$ may vary with rock types and soil properties (Sondenâ et al., 1990). For instance, in some carbonate formations, the value of $n$ could vary from 1.5 to 3 due to the complex pore structures (Longeron, 1990). Bekri et al. (2003) demonstrated that $n$ increased with the decreasing porosity of the reconstructed 3-D porous media $(0.26-0.44)$ and was affected by the 

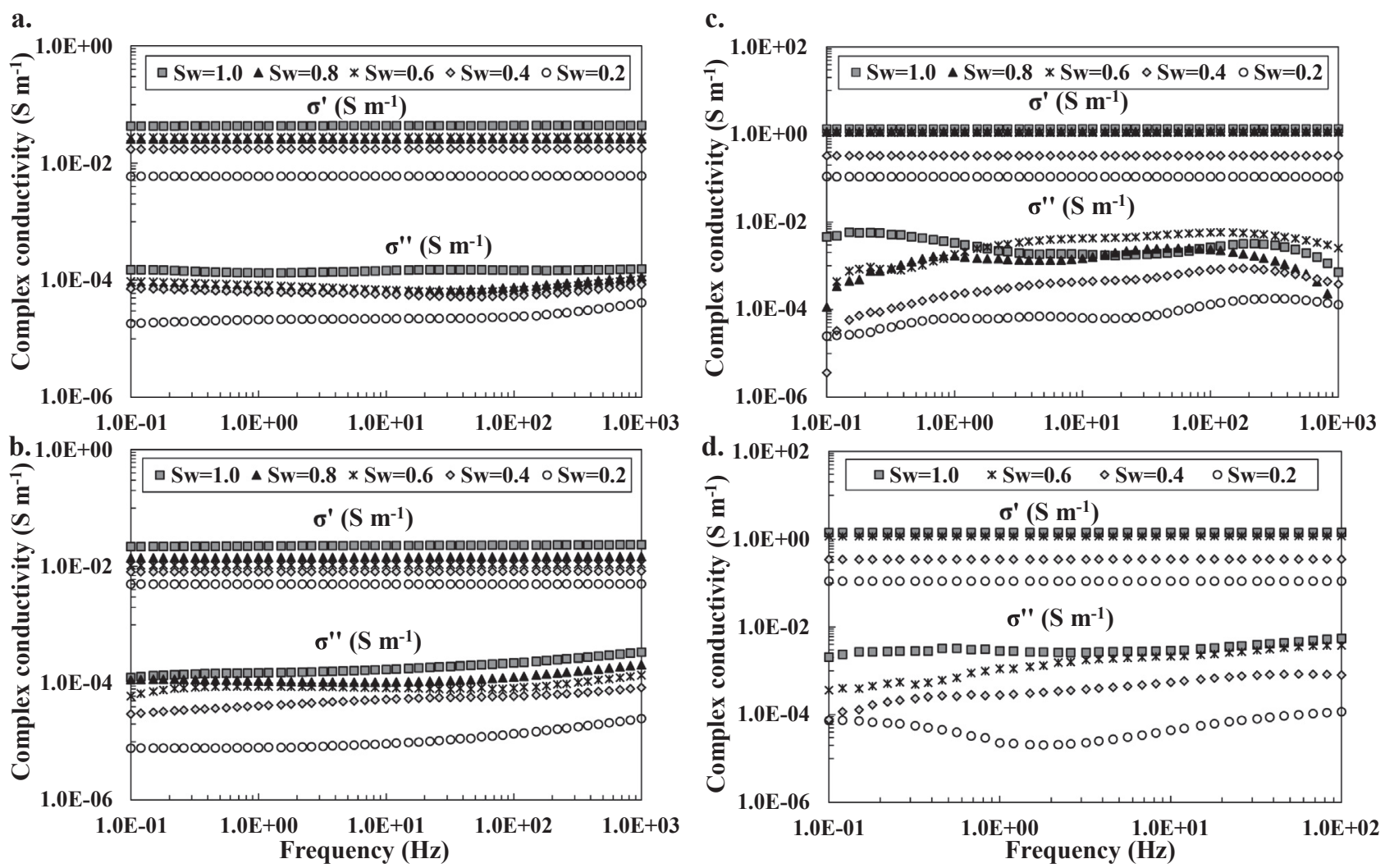

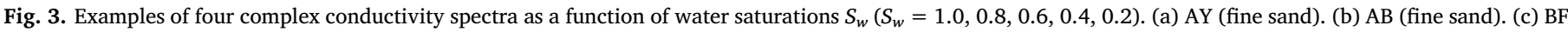
(sandy clay). (d) BG (clay). $\sigma^{\prime}$ denotes the in-phase conductivity $\left(\mathrm{S} \mathrm{m}^{-1}\right), \sigma^{\prime \prime}$ is the quadrature conductivity $\left(\mathrm{S} \mathrm{m}^{-1}\right)$.

spatial directions with respect to the liquids flow. The quadrature conductivity also follows a power law relationship with the saturation. This relationship was first proposed by Vinegar and Waxman (1984):

$\sigma^{\prime \prime}\left(S_{w}\right)=\sigma_{\left(S_{w}=1.0\right)}^{\prime \prime} S_{w}^{p}$

where $\sigma^{\prime \prime}$ is the quadrature conductivity, $\sigma_{\left(S_{w}=1.0\right)}$ is the quadrature conductivity at fully water saturated, $p$ denotes the quadrature conductivity exponent (following an additional power relationship with the saturation exponent $p=n-1$, see Vinegar and Waxman (1984) and Revil (2013b)). Studies have shown that $p$ can be positive or negative due to different oil types (Schmutz et al., 2012). Besides understanding the variations of these exponents with material properties, it's also necessary to further test the validation of the relationship $p=n-1$ for different soils.

Finally, the applications of the SIP method mostly focused on the hydrocarbon contamination in clean sand (Schmutz et al., 2012; Abdel Aal and Atekwana, 2014), however, few works have done on the SIP response of oil in clayey soils due to its complexity compared to clean sand. Therefore, there is still a gap of knowledge that needs to be filled if we want to apply the SIP method to oil spills problem in the field.

In this study, we first perform a set of SIP measurements on clayey soils under different oil saturations through laboratory column experiments. The purpose of the column experiments is to study the influences of soil and water properties on the saturation $n$ and the quadrature conductivity $p$ exponents, as well as validating the empirical relationship between $n$ and $p$. We further conduct a sandbox experiment to investigate the feasibility of the SIP method for mapping the contaminant plume and quantifying the oil volume. Our study is supposed to provide a new means of contamination characterization for oil-contaminated sites from the conceptual stage to the practice.

\section{Complex conductivity}

Induced polarization (IP) characterizes a phenomenon associated with the reversal storage process of electrical charges. The SIP method is an extension of the IP technique, depicting the polarization mechanism at grain/water interfaces over a wide range of frequencies (typically from $1 \mathrm{mHz}$ to few $\mathrm{kHz}$ ). The SIP response is generally described by complex conductivity spectra, which are determined from the measurement of the magnitude $(|\sigma|)$ and the phase shift $(\varphi)$ between the injected current and observed voltage for a range of frequencies. The complex conductivity $\left(\left|\sigma^{*}\right|\right)$ consists of two components: the real part (in-phase conductivity, $\sigma^{\prime}$ ) and the imaginary part (quadrature conductivity, $\sigma^{\prime \prime}$ ). Their relationship can be expressed as follows (e.g., Vinegar and Waxman, 1984):

$\sigma^{*}=|\sigma| \exp (i \varphi)=\sigma^{\prime}+i \sigma^{\prime \prime}$

$|\sigma|=\sqrt{\left(\sigma^{\prime 2}+\sigma^{\prime \prime 2}\right)}$

$\tan \varphi=\frac{\sigma^{\prime \prime}}{\sigma^{\prime}}$

where $i=(-1)^{1 / 2}$ denotes the pure imaginary number.

Typically, two mechanisms are used to characterize the polarization of a soil within low frequencies $(<100 \mathrm{~Hz})$. One of these mechanisms is the polarization of the inner component of the electrical double layer (EDL) coating the surface of the grains, the so-called Stern layer polarization. It describes the tangential movement of mobile counterions in the Stern layer under an alternating electrical field (Schwarz, 1962; Revil and Florsch, 2010). The Stern layer polarization is based on the assumption that the Stern layer is discontinuous and the diffuse layer is continuous in porous media (Leroy et al., 2008). According to the Stern layer polarization model, the polarization effect is associated either with the grain size or pore size distribution and surface conductivity 

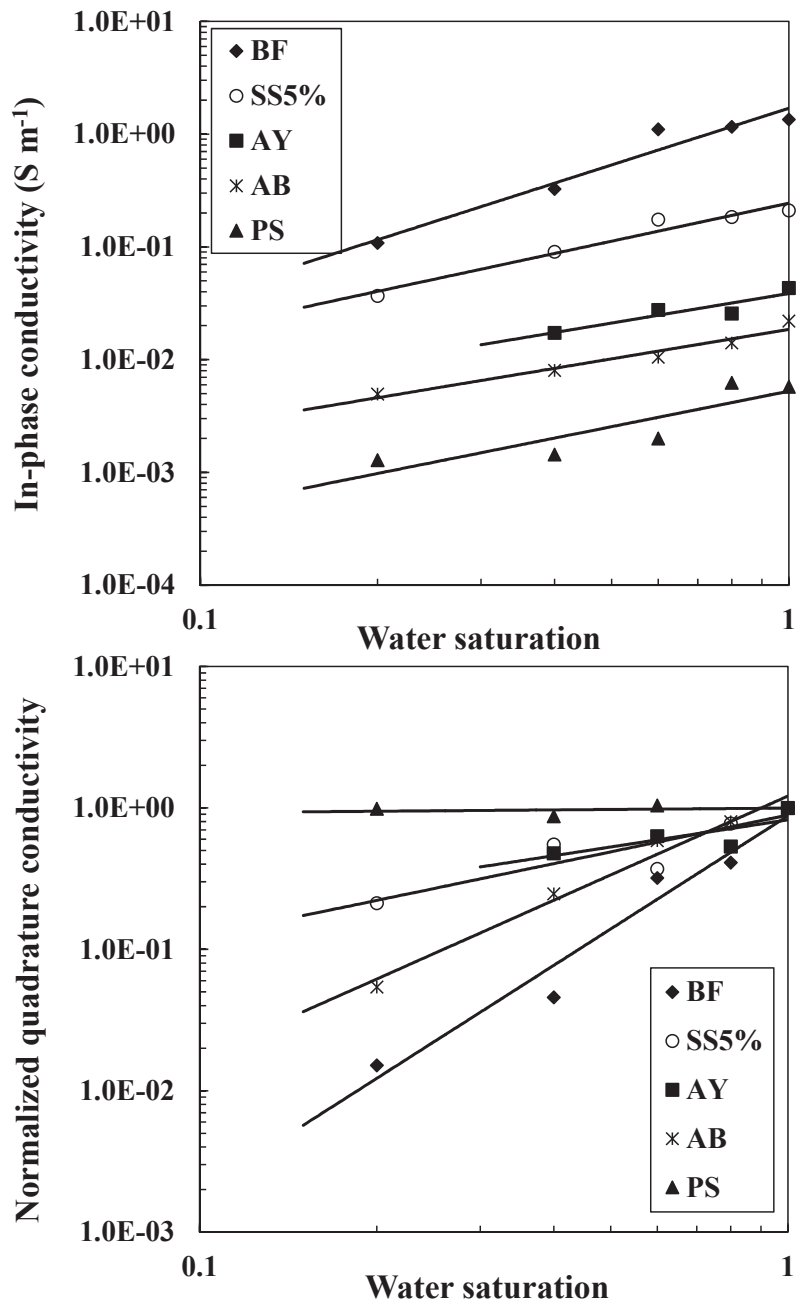

Fig. 4. The in-phase (upper) and normalized quadrature conductivities (lower) versus water saturation $\left(S_{w}\right)$ for five soils: BF (clay) $(1 \mathrm{~Hz})$, SS5\% (95\% clean sand and $5 \%$ smectite) $(0.15 \mathrm{~Hz}), \mathrm{AY}$ (fine sand) $(0.1 \mathrm{~Hz}), \mathrm{AB}$ (fine sand) $(0.1 \mathrm{~Hz})$ and PS (pure sand) $(0.1 \mathrm{~Hz})$. The normalized quadrature conductivity is defined as the ratio of quadrature conductivity at $S_{w}<1.0$ to quadrature conductivity at $S_{w}=1.0$.

(Revil and Florsch, 2010; Revil et al., 2012b). The second polarization mechanism is membrane polarization which is associated with the back-diffusion of the salt in pore space, as a result of the salt concentration difference around grains in an applied electrical field (e.g., Revil and Florsch, 2010). The membrane polarization generally occurs at the interconnected space between ion-selective (active) and non-selective (passive) zones caused by the difference in pore size or the presence of clay minerals.

Due to the broad grain size distributions of clayey materials, the phase is approximately constant with frequency in low-frequency range (see Revil et al., 2017). Therefore, both in-phase and quadrature conductivities are nearly independent of the frequency for a broad range of frequencies (see discussions in Vinegar and Waxman, 1984). For unsaturated material where the pore space is filled with multiphase fluids (e.g., water and oil/air), previous studies has concluded that both inphase and quadrature conductivities exhibit power-law dependency on water saturation (Vinegar and Waxman, 1984). As mentioned in Section 1, the relationship between the quadrature conductivity and water saturation is generally described by Eq. (2). According to Revil (2013a), the in-phase conductivity as a function of water saturation $\left(0 \leq S_{w} \leq 1\right)$ in low-frequency can be expressed as following:
$\sigma^{\prime}\left(S_{w}\right)=\frac{1}{F} S_{w}^{n} \sigma_{w}+S_{w}^{n-1} \sigma_{s}$

where $n$ denotes the exponent for in-phase conductivity (Vinegar and Waxman, 1984; Schmutz et al., 2012; Revil, 2013b), $F=\phi^{-m}$ (in first Archie's law, see Archie, 1942) is the formation factor ( $m$ is the cementation exponent and $\phi$ is the porosity), $\sigma_{w}$ is the pore water conductivity $\left(\mathrm{S} \mathrm{m} \mathrm{m}^{-1}\right), \sigma_{\mathrm{s}}\left(\mathrm{S} \mathrm{m}^{-1}\right)$ is the surface conductivity which is controlled by the cation exchange capacity (CEC) (in meq/100 g, converted to the international system of units $\mathrm{C} \mathrm{kg}^{-1}, 1 \mathrm{meq} /$ $100 \mathrm{~g}=963.2 \mathrm{C} \mathrm{kg}^{-1}$ ) (Revil and Florsch, 2010).

\section{Column experiments}

\subsection{Soil samples}

The soils we used for the experiments were originally collected from the Walcheren peninsula in the Netherlands (Revil et al., 2017). These soils were characterized by relatively high cation exchange capability (CEC). Eight sediment samples were tested in this study, including four fine sands, three sandy clays and one clay sample. In order to complement the soil samples, we also constructed other four samples: one sample of pure sand (sample PS), one mixture of $95 \%$ pure sand and $5 \%$ smectite (sample SS5\%), one sandy clay (sample AR) and one clay sample with a low CEC (sample RP). Therefore, there are in total 12 soil sediments studied in this work. The properties of these soils are summarized in Table 1.

\subsection{Complex conductivity measurement}

All the samples were packed in polypropylene columns with an inner diameter of $2.55 \mathrm{~cm}$ and a height of $6.25 \mathrm{~cm}$ (Fig. 1). The reasons for using such sample size were twofold. For one reason, such size was very similar to the size of a core plug which was the classical size used for most of the petrophysical studies. Successful SIP measurements have already been performed on the small plugs with four-electrode measuring system by Vinegar and Waxman (1984) and Revil et al. (2017). For another, since the clayey soils were collected from the in situ sampling, the amount was limited for performing SIP measurements with five different saturations using a larger sample holder. Similar four-electrode configuration was applied to perform the spectral induced polarization measurements in this study. Two current electrodes were self-adhesive super conductive carbon film, carbon/Ag/AgCl electrodes with biocompatible hydrogel widely used in medical field. They were located at the end-faces of the sample holder crossing the whole sample diameter. In order to reduce the contact impedance between the electrodes and sample, we saturated the gel on the surface of the medical electrodes with the same saline water used for saturating soil sample before SIP measurement. Two potential electrodes, made of $\mathrm{Ag} / \mathrm{AgCl}$, were placed just above the sample surface by cutting two small windows along the column. The same soil materials were filled between electrodes and sample to obtain a better electrical contact. Since the geometry of the sample holder was really simple, the geometrical factor was directly determined by $K=L / A$ where $K$ is the geometrical factor in $\mathrm{m}^{-1}, L$ is the distance between the two potential electrodes in $\mathrm{m}, A$ (in $\mathrm{m}^{2}$ ) denotes the surface area of the cross-section of the sample. The calculated geometrical factor is $47 \mathrm{~m}^{-1}$ for all the laboratory column experiments performed in this study.

The impedance and phase shift were measured by the ZEL-SIP04V02 impedance spectrometer over a frequency range of $10 \mathrm{mHz}-45 \mathrm{kHz}$. This impedance spectrometer is characterized by its high phase accuracy and high resolution with an accuracy better than $0.1 \mathrm{mrad}$ below $1 \mathrm{kHz}$ (Zimmermann et al., 2008). The applied voltage was set to $5 \mathrm{~V}$ for all the measurements. 

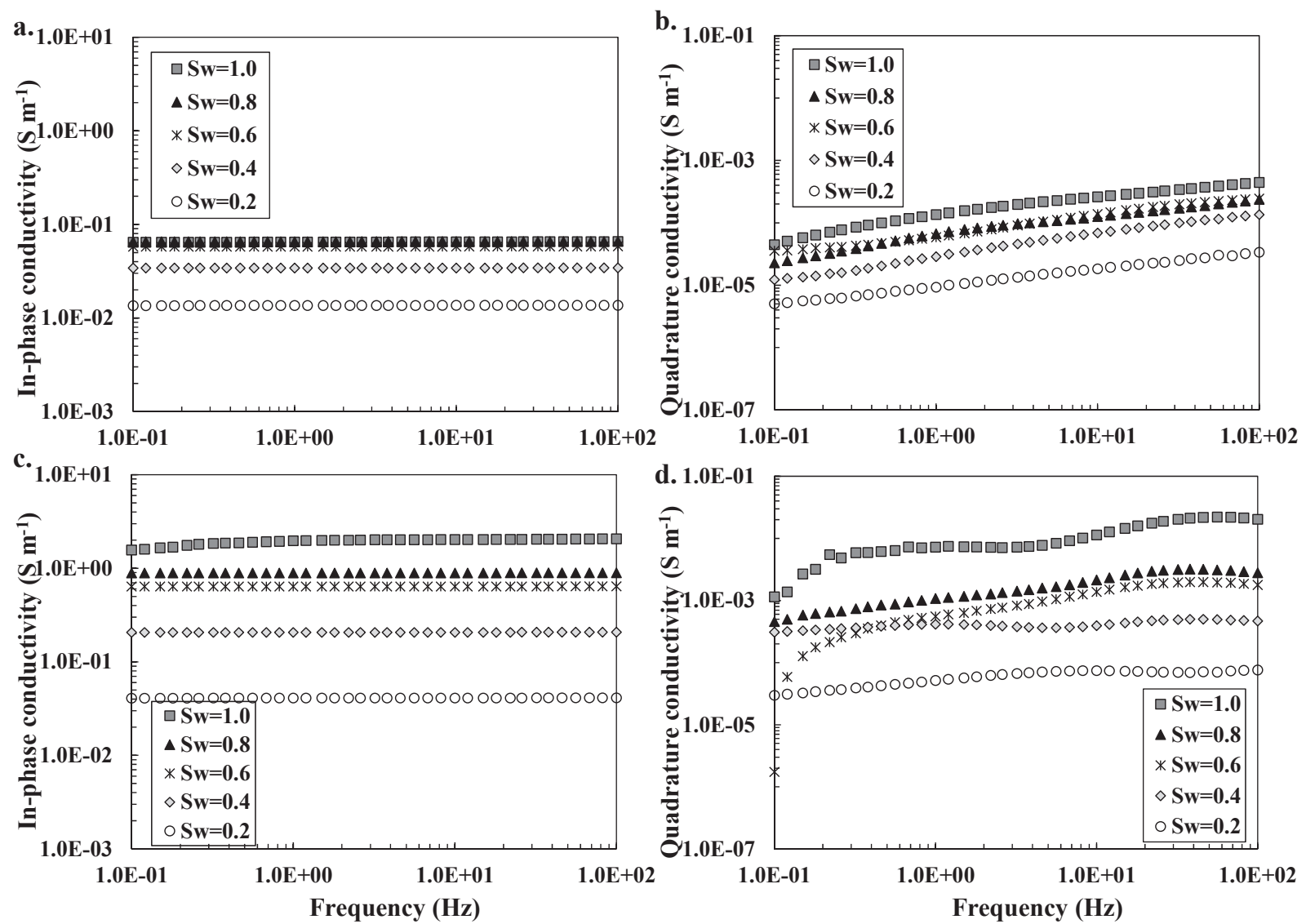

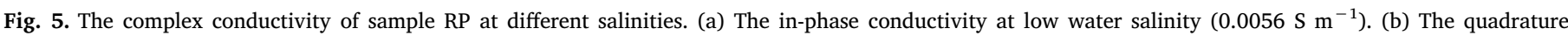

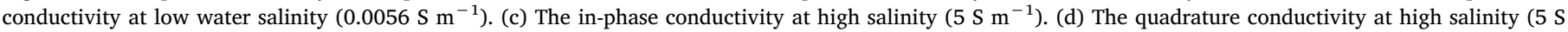
$\left.\mathrm{m}^{-1}\right)$.

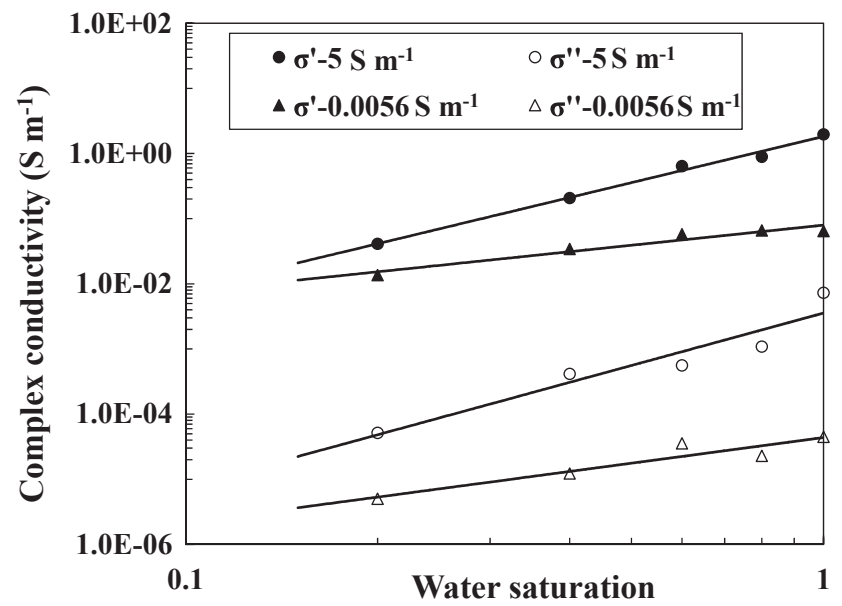

Fig. 6. The complex conductivity of sample RP as a function of water saturation. Data taken at $0.1 \mathrm{~Hz}$ for the low salinity sample and $1 \mathrm{~Hz}$ for the high salinity sample.

\subsection{Experimental procedure}

All the experiments were conducted under the same condition, at ambient laboratory temperatures around $22 \pm 3{ }^{\circ} \mathrm{C}$. In order to focus on the effects of oil on the SIP response of clayey soils, we only considered two-phase fluids including conductive water and non-conductive oil in pore space. We assumed that the air can be fully displaced from pore space during the compaction. This assumption was supported by the following two factors: firstly, the interfacial tension of decane-

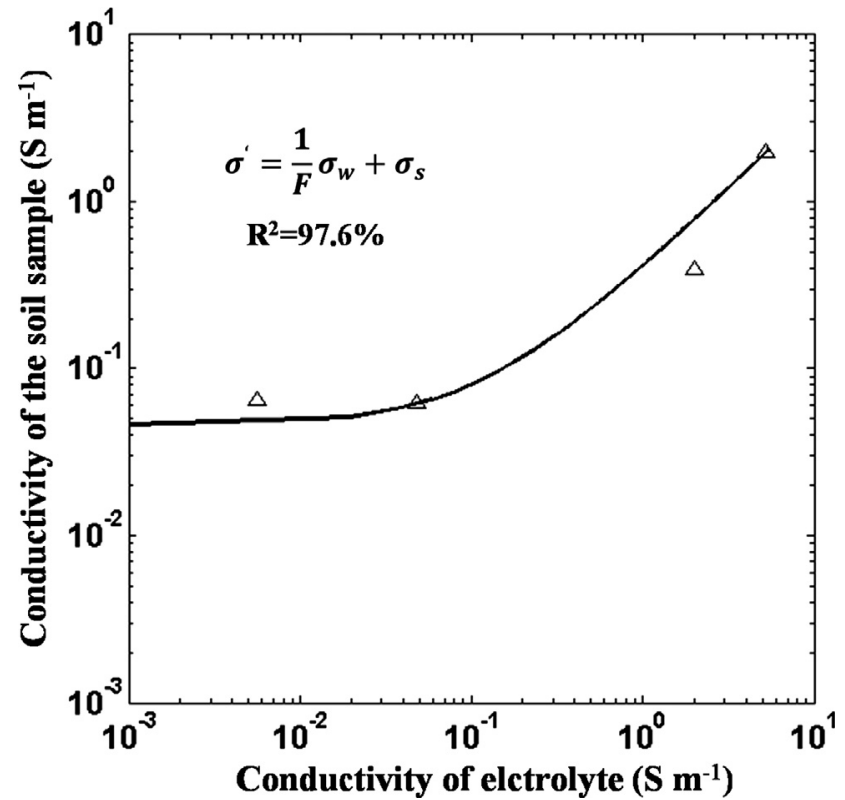

Fig. 7. The in-phase conductivity of soil versus pore water conductivity for the sample RP. $\sigma^{\prime}$ and $F$ denote the in-phase conductivity and formation factor, $\sigma_{w}$ and denote the pore water conductivity and $\sigma_{s}$ surface conductivity, respectively.

water interface $\left(52.33 \mathrm{mN} / \mathrm{m}, 20^{\circ} \mathrm{C}\right)$ is smaller comparing to that of the water-air interface $\left(72.75 \mathrm{mN} / \mathrm{m}, 20^{\circ} \mathrm{C}\right.$ ) (Vargaftik et al., 1983; Zeppieri et al., 2001), resulting in the sooner spread of oil to adjacent 
Table 2

Values of the quadrature conductivity exponent $p$ and the saturation exponent $n$ calculated from spectral induced polarization measurements.

\begin{tabular}{lll}
\hline Soil ID & $p$ & $n$ \\
\hline AB & 1.38 & 2.07 \\
AX & 1.21 & 2.20 \\
AY & 0.82 & 2.02 \\
BL & 1.40 & 1.80 \\
BF & 2.48 & 2.12 \\
BJ & 1.42 & 2.02 \\
CD & 2.63 & 1.85 \\
BG & 2.53 & 2.11 \\
AR & 1.15 & 1.80 \\
RP & 1.31 & 1.94 \\
PS & 0.03 & 1.56 \\
SS5\% & 0.96 & 1.88 \\
\hline
\end{tabular}

pore space during the compaction (Mercer and Cohen, 1990; Culligan et al., 2006); secondly, the relatively high fluid density ratio of oil to air is responsible for the displacement of air from pore space as well (Newell et al., 1991). For each soil sediment, SIP measurements were performed with five different water saturations $\left(S_{w}\right)$, i.e. $S_{w}=1.0,0.8$, $0.6,0.4,0.2$, corresponding to five different oil saturations $\left(S_{\mathrm{o}}\right)$, i.e. $S_{\mathrm{o}}=0,0.2,0.4,0.6,0.8$. According to previous studies (Niu et al., 2016), the water with a salinity below $0.01 \mathrm{~S} \mathrm{~m}^{-1}$ is typically considered as the low-salinity water while the water with a salinity above 1 $\mathrm{S} \mathrm{m}^{-1}$ is supposed to be the high-salinity water. The water used in this study was a $\mathrm{NaCl}$ solution with an average salinity of $0.0056 \mathrm{~S} \mathrm{~m}^{-1}$, which would act as a representative of fresh water environment. Decane, a nonpolar hydrocarbon, was selected as non-aqueous phase liquid (NAPL) for all the partially saturated experiments. It has a density of $0.73 \mathrm{~kg} \mathrm{~m}^{-3}$ at $25^{\circ} \mathrm{C}$. Prior to the experiment, the soil was first airdried and then ground with the grinding bowl.

For the sample preparation, we first packed the column with dry soil tightly to obtain the soil mass. The amount of the soil was fixed. Next, a water saturated sample was compacted by adding few mm of water into the empty column followed by a small amount of soil. This step was repeated until the entire column was filled. In order to ensure the soil fully water saturated, a water surface was maintained just above the soil during the whole compaction. The required pore volume to completely saturate the soil was thus determined by the difference of the weight of fully water saturated and dry soil. For water-unsaturated samples, based on the determined pore volume, the amount of water and oil was calculated to achieve the desired water saturation (i.e. $S_{w}=0.8,0.6,0.4,0.2$ ). For this case, we first mixed the soil with the saline water then with oil in a glass beaker. Following the mixing, we packed the mixture tightly in the column. Similar packing procedures can be found in previous works (Schmutz et al., 2010; Abdel Aal and Atekwana, 2014). In order to verify the saturation, we compared the total mass of soil, water and oil used with the mass of the compacted sample for each soil. The obtained average percentage difference was $5 \% \pm 1 \%$, which might result from the reduction of the mass during the transference of the sample from beaker to the sample holder. The whole packing process was controlled within $40 \mathrm{~min}$. The spectral induced polarization measurements were conducted right after the packing of each sample.

The influence of sampling and repacking on the phase spectra of soil is minor as suggested by a comparison between the field and laboratory spectra (Vanhala and Soininen, 1995; Vanhala, 1997). We also constructed a benchmark experiment using two separate samples labeled as Test 1 and Test 2 with the same soil material (sample AX). This was done to investigate the effect of artificial packing on the complex conductivity spectra. The two samples were fully saturated with the same electrolyte ( $\mathrm{NaCl}$ solution, $0.0056 \mathrm{~S} \mathrm{~m}^{-1}$ ). The results demonstrated that the influence of the packing on the SIP signature is rather insignificant in our case (Fig. 2).

\subsection{Complex conductivity spectra of oil-contaminated soil}

We focus on the effect of oil addition on the electrochemical polarization which dominates in the low-frequency range $(0.01-1000 \mathrm{~Hz})$ (Leroy et al., 2008; Revil and Florsch, 2010). Therefore, only the results in the low-frequency range are presented for the following analysis.

Fig. 3 shows that the complex conductivity is saturation dependent, which is consistent with the previous studies on non-wetting oil (Vinegar and Waxman, 1984; Schmutz et al., 2010; Abdel Aal and Atekwana, 2014). No clear peak can be observed in the complex spectra, which might be due to the broad grain size of the clayey materials. For all soils, the magnitude of both in-phase and quadrature conductivities exhibit an overall tendency of decrease with decreasing water saturation, as a result of the reduction of conductive phase (water) and increase of non-conductive NAPL in pores (Schmutz et al., 2010; Abdel Aal and Atekwana, 2014). However, the complex conductivities does not change significantly with water saturation for slightly contaminated samples (e.g., $S_{\mathrm{o}}=0.2$ or equally $S_{w}=0.8$ ). This can be explained by the barrier mechanism proposed by Halihan et al. (2017), which demonstrated that the variations in electrical signature due to the presence of oil was controlled by its local oil saturation. The changes in resistivity could be non-detectable when the oil saturation was below a certain value. It thus can be inferred that it would be difficult to detect the variations of conductivity in soils contaminated with oil of low saturations for practical investigations. Compared to the slightly contaminated samples, there is a significant difference in the
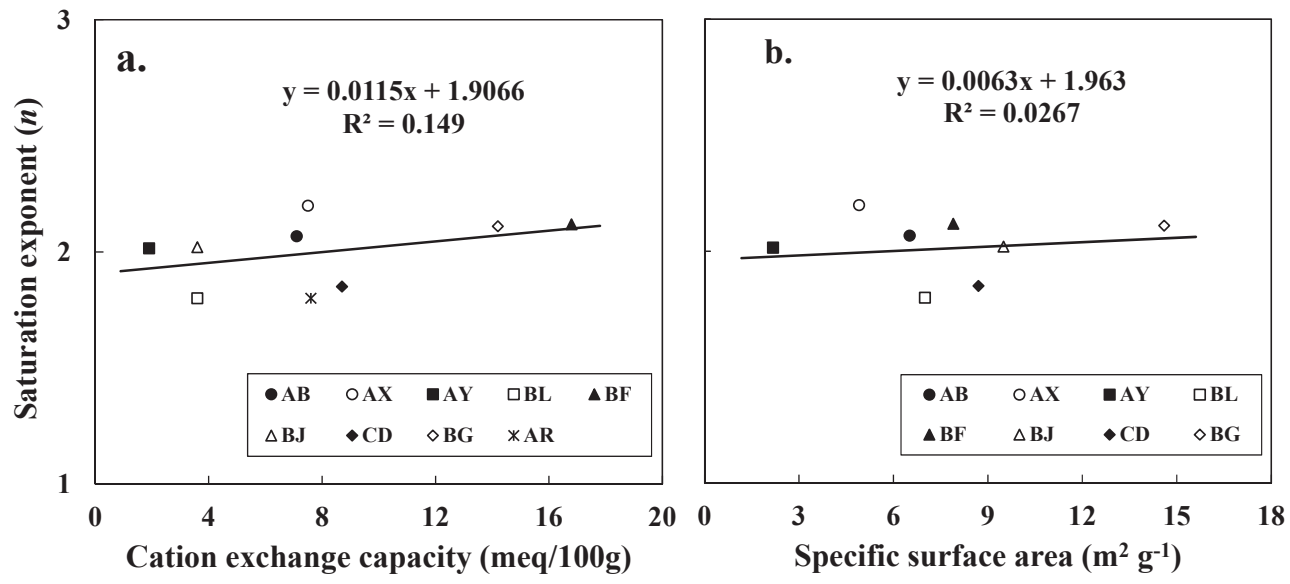

Fig. 8. Relationships between the measured saturation exponent $n$ and the cation exchange capacity (left panel) and the specific surface area (right panel). 

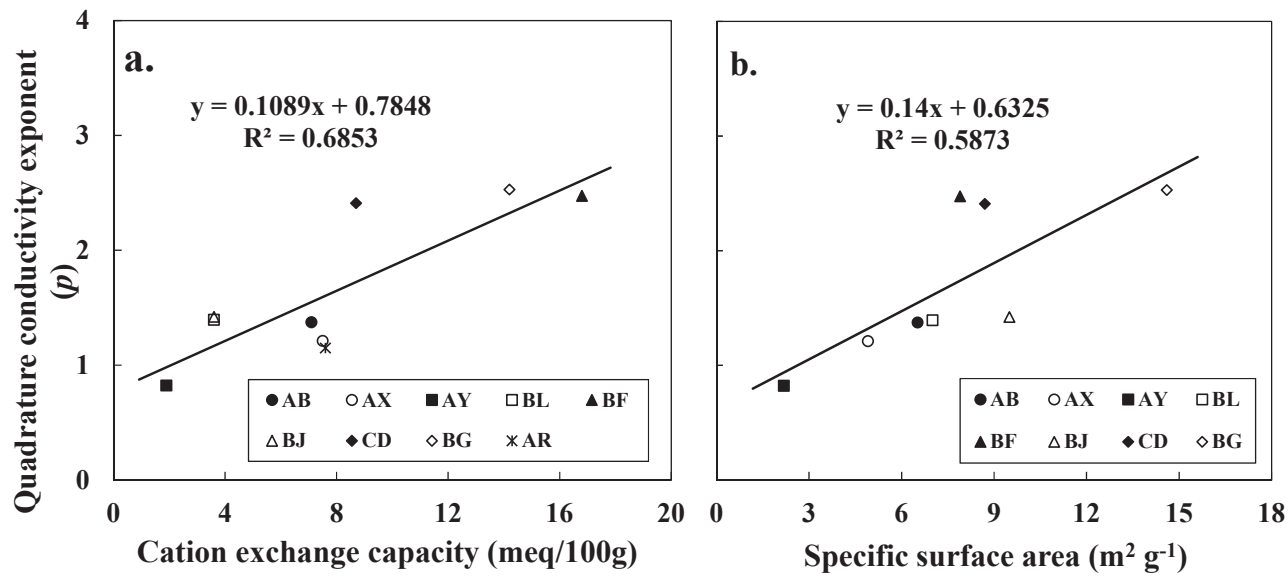

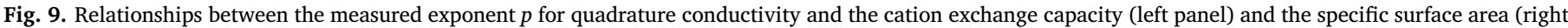
panel).

Table 3

Summary of the reported saturation exponent $n$ and quadrature conductivity exponent $p$ from the literature.

\begin{tabular}{|c|c|c|c|c|}
\hline Sample & Soil type & Non-wetting fluid & Measured $n$ & Measured $p$ \\
\hline Experiment \#A & Umimin sand $^{\mathrm{a}}$ & Industrial oil & 3.13 & 1.97 \\
\hline Experiment \#A & Umimin sand $^{\mathrm{a}}$ & Oil from oil reservoir & 2.14 & 1.26 \\
\hline Water-wet Fresh oil & Ottawa sands ${ }^{\mathrm{b}}$ & Fresh oil & 1.432 & 0.221 \\
\hline Water-wet Biodegraded oil & Ottawa sands ${ }^{\mathrm{b}}$ & From oill spill & 1.283 & 0.223 \\
\hline $5 \mathrm{P}-3 \mathrm{~A}$ & Sand $^{\mathrm{c}}$ & Heavy oil & 1.67 & 0.49 \\
\hline V104 & Clayey sand $^{\mathrm{d}}$ & Crude oil & 2.17 & 1.18 \\
\hline V106 & Clayey sand ${ }^{\mathrm{d}}$ & Crude oil & 2.43 & 1.28 \\
\hline V110 & Clayey sand ${ }^{\mathrm{d}}$ & Soltrol & 2.11 & 1.27 \\
\hline V112 & Clayey sand ${ }^{\mathrm{d}}$ & Soltrol & 1.63 & 0.78 \\
\hline 1883 & Clayey sand ${ }^{\mathrm{d}}$ & Soltrol & 1.81 & 1.2 \\
\hline 3371 & Clayey sand ${ }^{\mathrm{d}}$ & Soltrol & 2.4 & 1.17 \\
\hline $3372 \mathrm{C}$ & Clayey sand ${ }^{\mathrm{d}}$ & Soltrol & 2.35 & 1.16 \\
\hline 3374 & Clayey sand ${ }^{\mathrm{d}}$ & Soltrol & 1.79 & 0.93 \\
\hline $3307 \mathrm{C}$ & Clayey sand ${ }^{\mathrm{d}}$ & Soltrol & 1.89 & 1.03 \\
\hline $55-60$ & Sand $^{\mathrm{e}}$ & Air & 1.3 & 0.6 \\
\hline Sample A & Fine sand $d^{f}$ & Air & 1.01 & 0.41 \\
\hline Sample E & Sand $^{\mathrm{f}}$ & Air & 1.23 & 0.5 \\
\hline Sample H & Sand $^{\mathrm{f}}$ & Air & 2 & 1.4 \\
\hline Sample B & Sand $^{\mathrm{f}}$ & Air & 1 & 0.42 \\
\hline Sample C & Coarse sand ${ }^{\mathrm{f}}$ & Air & 1.28 & 0.61 \\
\hline Sample F & Sand $^{\mathrm{f}}$ & Air & 1.23 & 0.5 \\
\hline Sample G & Sand $^{\mathrm{f}}$ & Air & 2.7 & 0.94 \\
\hline Sample 1 & Sand $^{g}$ & Air & 1.38 & 0.61 \\
\hline
\end{tabular}

a Clean sand (from Schmutz et al., 2012)

b Clean sand (from Abdel Aal and Atekwana, 2014)

c Sand (from Martinez et al., 2012)

d Clayey sand (from Vinegar and Waxman, 1984)

e Sand (from Slater and Glaser, 2003)

${ }^{f}$ Unconsolidated sediments (from Ulrich and Slater, 2004)

g Sand (from Aal et al., 2006)

magnitude of complex conductivity between seriously contaminated (e.g., $S_{\mathrm{o}}=0.8$ or similarly $S_{w}=0.2$ ) and fully water saturated samples. The obvious decrease in the conduction and polarization at low water saturation might be caused by the discontinuity of the water films when the water saturation is below the critical values in porous media (Sarma and Rao, 1962; Keller and Frischknecht, 1966; Kumar et al., 2010).

\subsection{Influence of the pore water and soil properties on the exponents $n$ and $p$}

Since the complex conductivity is saturation dependent, we plot the in-phase and normalized quadrature conductivities as a function of water saturation (Fig. 4). As mentioned in Section 2, the complex spectra of clayey materials are approximately independent of the frequency for a broad frequencies, which is also the case in our study. Thus, we take the complex conductivity at a frequency where the quadrature spectra become flat. The normalized quadrature conductivity is defined as the ratio of the quadrature conductivity of partially water saturated samples to that of the sample fully water saturated. The slope of the trend line indicates the exponent of in-phase/ quadrature conductivity, the saturation $n$ and the quadrature conductivity $p$ exponents, respectively. It shows that there is a significant difference in the quadrature conductivity exponent among these different soil materials. For instance, the quadrature conductivity is almost independent of water saturation for the sample PS (pure sand). While for the sample BF (sandy clay), there is a strong dependence of quadrature conductivity on water saturation. Contrast to the quadrature conductivity, the slope of the trend lines connecting the in-phase conductivity and water saturation is almost similar for each soil except the sandy clay with a slightly steeper slope. These differences in slope indicate a potential influence of soil properties on the saturation and 


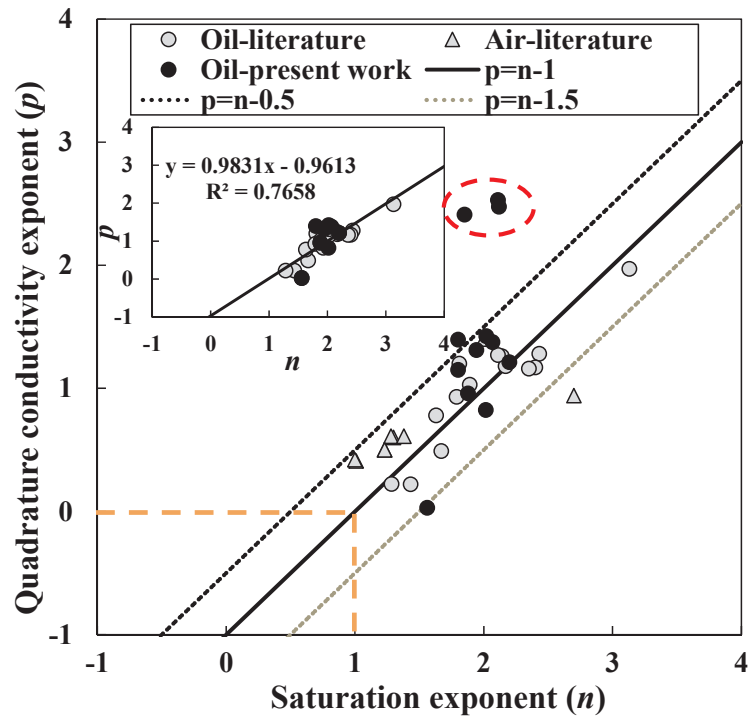

Fig. 10. The measured exponent for the quadrature conductivity $p$ versus the saturation exponent $n$ describing the in-phase conductivity dependence with the saturation. Insert: the best fit for the oil contaminated samples except for the soils characterized by a high value of the cation exchange capacity (normally greater than $10 \mathrm{meq} / 100 \mathrm{~g}$ ). Note that $n$ cannot be smaller than 1 and therefore $p$ cannot be smaller than 0 , the area indicated by the orange dashed line. (For interpretation of the references to colour in this figure legend, the reader is referred to the web version of this article.)

quadrature conductivity exponents, which will be further discussed in the following.

Previous experimental studies have shown the significant influences of salinity on the complex conductivity of porous media (Lesmes and Frye, 2001; Revil and Skold, 2011). In order to investigate the effect of pore water salinity on the exponents $n$ and $p$, a contrasting experiment was constructed at two different pore water salinities $(0.0056$ versus $5 \mathrm{~S}$ $\mathrm{m}^{-1}$ ) for the same soil (sample RP) (Fig. 5). The case with a water salinity of $0.0056 \mathrm{~S} \mathrm{~m}^{-1}$ corresponds to the low-salinity (fresh) environment while the case with a salinity of $5 \mathrm{~S} \mathrm{~m}^{-1}$ represents for a high-salinity (highly saline) environment. A significant increase in the magnitude of the complex conductivity is observed when the salinity increases from $0.0056 \mathrm{~S} \mathrm{~m}^{-1}$ to $5 \mathrm{~S} \mathrm{~m}^{-1}$. As shown in Fig. $5 \mathrm{~b}$ and $\mathrm{d}$, the shape of quadrature conductivity spectra at $5 \mathrm{~S} \mathrm{~m}^{-1}$ is very different from that at $0.0056 \mathrm{~S} \mathrm{~m}^{-1}$. Compared to the curve at high-salinity, the curve at low-salinity appears to be flatter, which is also indicated by the previous studies from Weller and Slater (2012) and Revil et al. (2013). This behavior can be explained by the change in the thickness of the diffusive layer which depends inversely on the square root of salinity (Hördt et al., 2016). According to the conceptual model previously proposed by Titov et al. (2002), the diffusive layer is supposed to become thinner with increasing salinity and eventually become significant only in the narrow pore. As a result, the phase shift reaches the maximum. Thus we suppose that the change in spectra shape at high-salinity is due to the diminishment of the thickness of the diffusive layer caused by an increasing salinity. As the salinity increases, the difference of the magnitude of the complex conductivity between fully and partially water saturated samples becomes more prominent. In other words, it's easier to distinguish clean and contaminated soil under high salinity.

Fig. 6 plots both in-phase and quadrature conductivities as a function of water saturation for two water salinities for sample RP. The results indicate that the slope of in-phase and quadrature conductivities with respect to saturation for low salinity is apparently flatter comparing to that for high salinity. Prior to calculating the exponents $n$ and $p$, we determine the formation factor $F$ and surface conductivity $\sigma_{s}$ by plotting the real part of the complex conductivity versus the
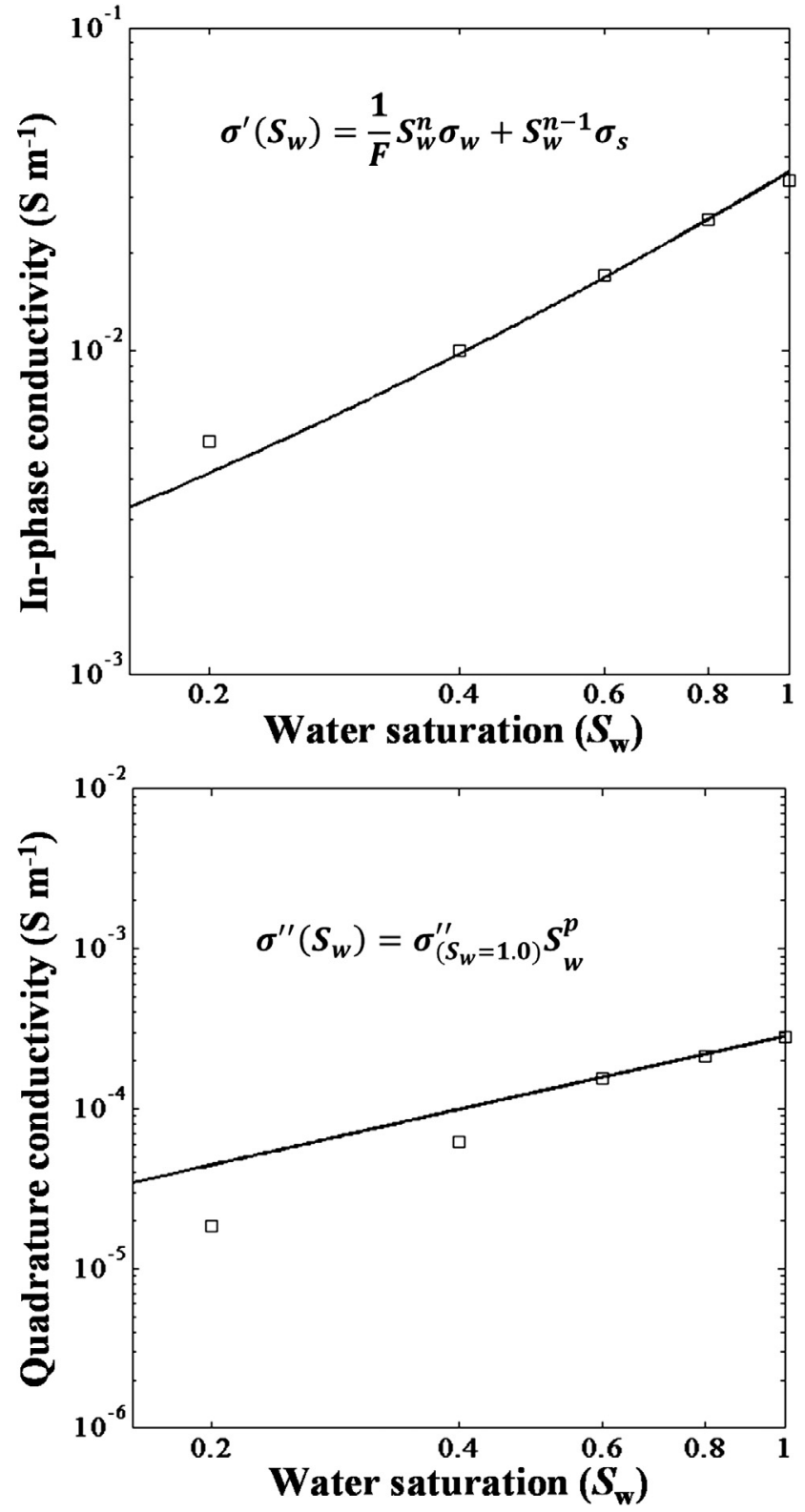

Fig. 11. Relationships between the in-phase (upper) and quadrature (lower) conductivities versus the water saturation at $0.1 \mathrm{~Hz}$ (sample AR). The black line indicates the fitting curve.

conductivity of pore water (Fig. 7). The obtained $F$ and $\sigma_{s}$ for sample RP are 2.71 and $0.04 \mathrm{~S} \mathrm{~m}^{-1}$, respectively. We subsequently calculate the saturation $n$ and quadrature conductivity $p$ exponents for the two salinities with Eqs. (2) and (6). Therefore, we obtain exponents of 1.94 for $n$, and 1.31 for $p$ at low salinity $\left(0.0056 \mathrm{~S} \mathrm{~m}^{-1}\right)$, while for high salinity $\left(5 \mathrm{~S} \mathrm{~m}^{-1}\right.$ ), the exponents increase to 2.49 for $n$, and 2.67 for $p$. Similar results were also obtained by Argaud et al. (1989) who found a lower $n$ exponent at lower salinity. According to Nasralla et al. (2013), low salinity water leads to a greater repulsion forces at solid/water and water/oil interfaces which makes the water films surrounding the grain become thicker, resulting in a more water-wet system. The thickness of the water film is related to the saturation exponent $n$ with a smaller $n$ value corresponding to a thicker water film (Toumelin and TorresVerdin, 2005). Therefore, the increase in the saturation and quadrature conductivity exponents at high water salinity observed in this study could be a result of change of electric charges with increasing water salinity.

We further explore the effect of soil properties, including cation 
(a)
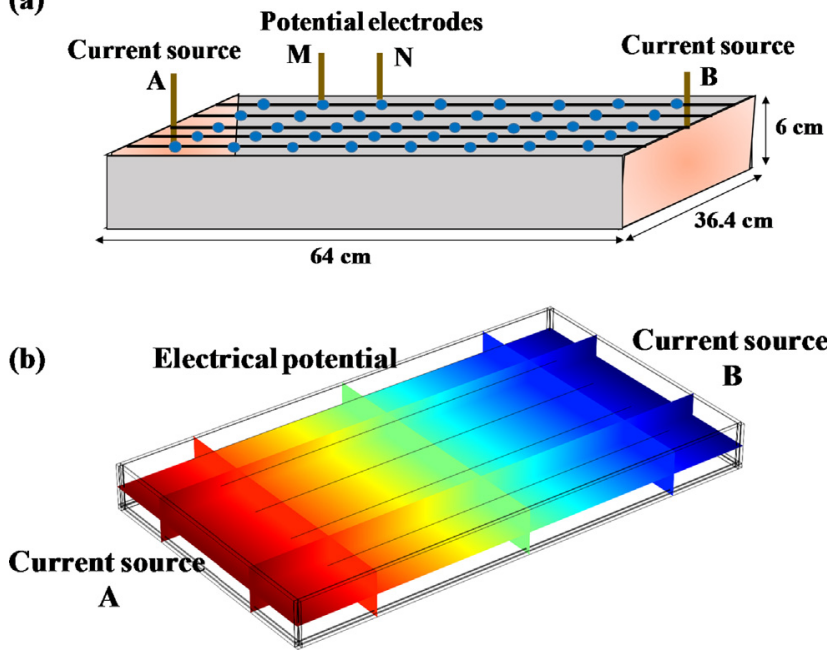

Fig. 12. (a) Sketch of the experimental sandbox showing the setup of the electrodes used for the complex conductivity measurements. The current sources A, B are aluminum foils. The potential electrodes $\mathrm{M}, \mathrm{N}$ are non-polarizable $\mathrm{Ag} / \mathrm{AgCl}$ electrodes; (b) The simulated electrical potential distribution by COMSOL Multiphysics used to compute the geometrical factor.
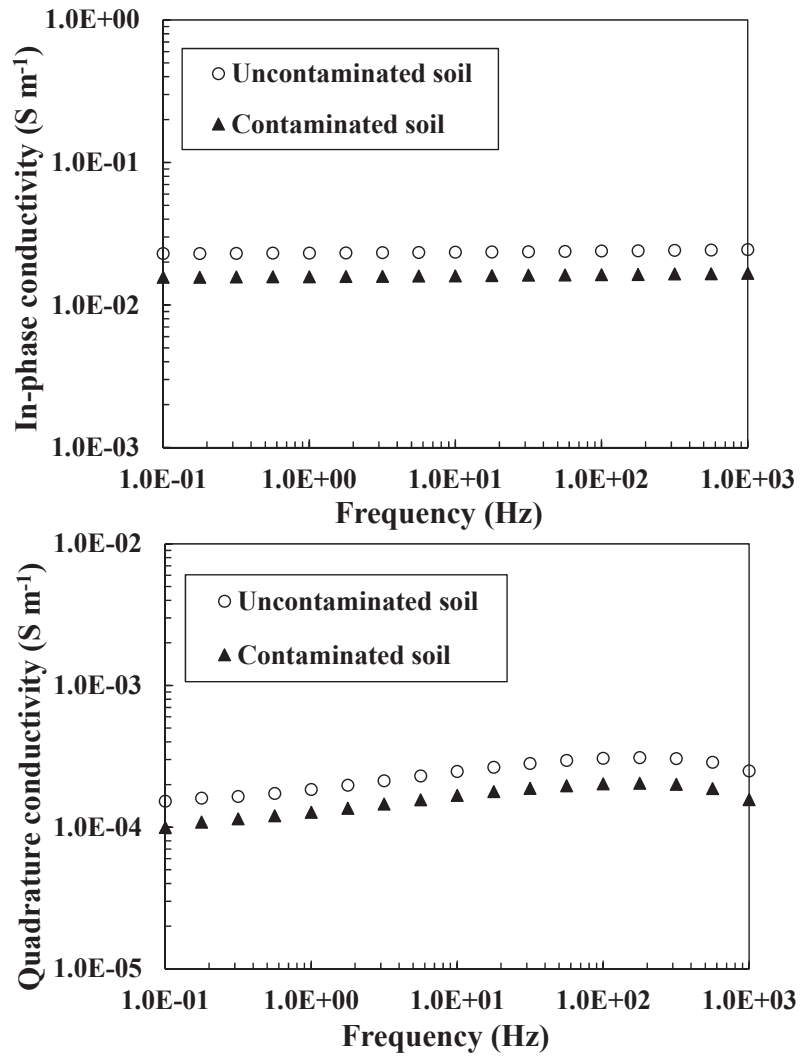

Fig. 13. Spectra of the in-phase (upper) and quadrature (lower) conductivities versus frequency before and after contamination at one point. The position of the chosen point is indicated by a red square in Fig. 14 .

exchange capacity and specific surface area, on the exponents $n$ and $p$. Following the same procedure as sample RP, the calculated saturation and quadrature conductivity exponents for all soils in present work are summarized in Table 2. The information of $F$ and $\sigma_{s}$ for these soils are collected from the work of Revil et al. (2017). The saturation exponent increases marginally with the cation exchange capacity and specific surface area, with an average value of 2.01 (Fig. 8). Compared to the saturation exponent, the quadrature conductivity exponent shows a more significant tendency to increase with increasing cation exchange capacity and specific surface area (Fig. 9). In general, both exponents exhibit a closer correlation with cation exchange capacity compared to the specific surface area.

As reported by Revil et al. (1998), the cementation exponent, which represents the rate of change of the connectedness with porosity and connectivity, showed a clear increase with increasing cation exchange capacity. In general, the value of the cementation exponent increases as the degree of connectedness decreases. Hence, the degree of connectedness is supposed to decrease with the increase of the cation exchange capacity. Since the cation exchange capacity is generally related to the content and composition of clay, the decrease of the water connectedness might be caused by the presence of clay, which further affects the saturation and quadrature conductivity exponents. According to Wang and Sharma (1988), the saturation exponent tended to be related to the connectedness of the water phase with lower water connectedness corresponding to a higher value of exponent. The water connectedness is defined as the inverse of the Archie's formation factor. For our case, though the cation exchange capacity of the soils varies from 1.9 to $16.8 \mathrm{meq} / 100 \mathrm{~g}$, the corresponding formation factor does not change a lot (Table 1 ). Thus, the saturation exponent only slightly increases with the cation exchange capacity.

It should be noted that the quadrature conductivity exponent seems to be more sensitive to the presence of clay minerals compared to the saturation exponent (Figs. 8 and 9). This might be caused by the contribution of the nonlinear membrane polarization due to the presence of clay minerals. At low frequencies $(<1 \mathrm{~Hz})$, in addition to the Stern layer polarization, the membrane polarization also plays a role in the polarization of clay-rich materials (Leroy and Revil, 2009). As pointed by Vinegar and Waxman (1984), at low CEC $\left(Q_{v} \leq 0.1 \mathrm{meq} / \mathrm{ml}\right)$, the membrane lockage contribution to the polarization was negligible, while the membrane blockage effect became significant with increasing clay content. Addition of oil changes the original geometry of conductive phase (water) and might cause a rearrangement of clay immersed in pore water (Breede and Kemna, 2012). As water saturation decreases, the clay minerals are consequently restricted in a narrower pore volume. This rearrangement of clay minerals probably results in an obstruction in conductive path for current flow and thus affects the membrane polarization (Titov et al., 2004; Breede and Kemna, 2012).

\subsection{Relationship between the exponents $n$ and $p$}

In order to evaluate the empirical relationship between the saturation exponent $n$ and the quadrature conductivity exponent $p$, we collected additionally reported data from literatures (see Table 3). All these data are plotted in Fig. 10 together with the data in the present work. It demonstrates that $p$ does not strictly obey to the relationship $p=n-1$ first proposed by Vinegar and Waxman (1984). Instead, it mostly ranges between $p=n-1.5$ and $p=n-0.5$. For the samples beyond $p=n-0.5$ (as circled in red), they are characterized by abnormally high quadrature conductivity exponent and thus high cation exchange capacity. After eliminating these points, a best linear fit with $p=0.9831 n-0.9613$ with $\mathrm{R}^{2}=0.7658$ is obtained for all partially oil saturated samples. It could be found that the fitted relationship is very close to the empirical relationship $p=n-1$. This result is consistent with the conclusions for clay-free samples (Schmutz et al., 2012; Abdel Aal and Atekwana, 2014) and shaly sands with a CEC ranging from 0.52 to $6.20 \mathrm{meq} / 100 \mathrm{~g}$ (Vinegar and Waxman, 1984). Therefore, it can be concluded that the relationship $p=n-1$ fits well as a first approximation for the soils with low CEC which is less than $10 \mathrm{meq} / 100 \mathrm{~g}$. Such relationship, however, is not suitable for the soils with high cation exchange capacity (e.g., clay-rich materials). 

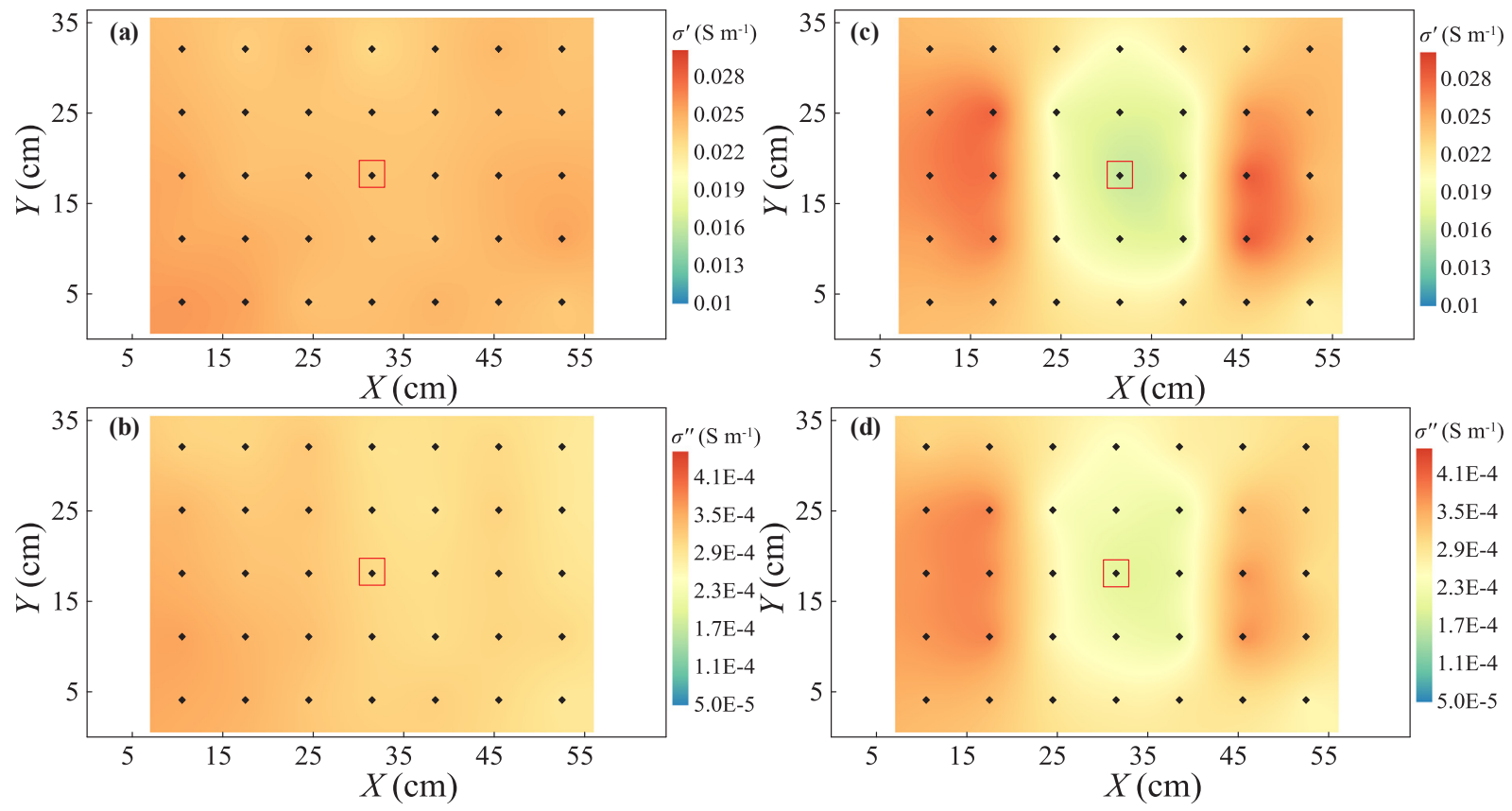

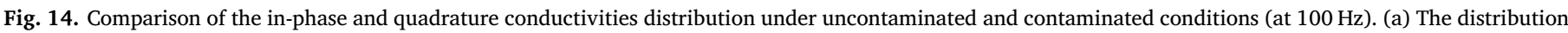

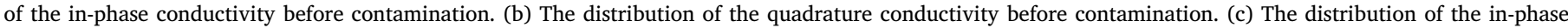

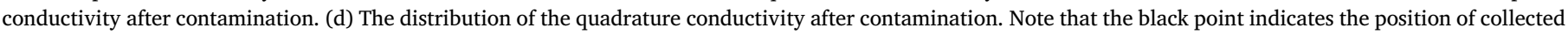
data.

\section{Sandbox experiment}

Based on the validated relationship between the complex conductivity and saturation in the column experiments (Eqs. (2) and (6)), a sandbox experiment was further conducted to evaluate the performance of the SIP technique in the quantification of oil amount.

\subsection{In-phase and quadrature conductivity exponents}

In order to acquire the parameters of $n$ and $p$ for the material used in the sandbox experiment, we conducted a series of SIP measurements on the natural soil with different oil saturations $\left(S_{\mathrm{o}}=0,0.2,0.4,0.6,0.8\right)$ in laboratory columns following the same procedure as described in Section 3.3. The soil (sample AR) used was sandy clay with a CEC of $7.6 \mathrm{meq} / 100 \mathrm{~g}$ and the water salinity was $0.1 \mathrm{~S} \mathrm{~m}^{-1}$. The CEC was obtained with the cobaltihexamine chloride method (Aran et al., 2008). Since the cobaltihexamine chloride solution is colored and absorbs at $472 \mathrm{~nm}$, the CEC value is derived from the absorbance of the cobaltihexamine chloride solution before and after the exchange between the cobaltihexamine chloride solution and the soil. The formation factor $F$ and surface conductivity $\sigma_{s}$, appearing in the Eq. (6) are determined by measuring the electrical conductivities at two different brine salinities $\left(0.05\right.$ and $\left.0.1 \mathrm{~S} \mathrm{~m}^{-1}\right)$. We obtained $F=4.35$ and $\sigma_{s}=0.01 \mathrm{~S} \mathrm{~m}^{-1}$, respectively.

Fig. 11 shows the relationship between complex conductivity and water saturations for sample AR. We applied the Eqs. (2) and (6) to get the exponents for in-phase and quadrature conductivities. The corresponding results are $1.8 \pm 0.2$ for $n$ and $1.15 \pm 0.17$ for $p$.

\subsection{Sandbox setup and data acquisition}

The sandbox used in this experiment had a dimension of $0.64 \times 0.364 \times 0.06 \mathrm{~m}^{3}$ (Fig. 12a). We first packed the same soil from bottom to top with the tap water which had a conductivity of $0.067 \mathrm{~S}$ $\mathrm{m}^{-1}$. The resultant bulk conductivity distribution was served as the background conductivity. Subsequently, we removed controlled volume of saturated soil $\left(0.20 \times 0.25 \times 0.04 \mathrm{~m}^{3}\right)$ and replaced the removed soil with the same volume of oil-contaminated soil in the center of the sandbox. Prior to preparing the oil-contaminated soil, a saturated soil sample was compacted in a column with known volume $\left(50 \mathrm{~cm}^{3}\right)$. We assume that the porosity of the oil-contaminated soil is the same as that in the column (the same soil). Thus, the amount of the soil to use could be determined by upscaling the column volume to the controlled volume. In other words, the soil mass needed was the product of the amount of soil in the known column and upscaling factor. The water and oil volume was then obtained by multiplying the pore volumes (determined by total volume and the porosity) by a certain ratio of water to oil. The volume of oil was $425 \mathrm{ml}$. The contaminated soil was prepared by mixing the soil and water, following by the oil in a container. The final step was to compact the contaminated soil in the center of the sandbox. Two SIP measurements were conducted before and after the oil contamination.

As shown in Fig. 12a, the SIP data acquisition system consisted of two rectangular aluminum foils as laminar current source at two sides of the sandbox, and five parallel lines crossing in the x-direction measuring the resultant voltages. Each survey line was composed of 8 nonpolarizable $\mathrm{Ag} / \mathrm{AgCl}$ electrodes with an electrode spacing of $0.07 \mathrm{~m}$. The distance between each line was also $0.07 \mathrm{~m}$. The data was collected with the ZEL-SIP04-V02 impedance spectrometer over a range of frequencies from $0.1 \mathrm{~Hz}$ to $10 \mathrm{kHz}$ (Zimmermann et al., 2008). There was totally 35 data collected over the whole sandbox each time. We used COMSOL Multiphysics 5.0 to simulate the current injection and voltage distribution in experimental sandbox to acquire the geometrical factor $K\left(\mathrm{~m}^{-1}\right)$, which was used in turn to interpret the impedance measurements (amplitude and phase spectra) in terms of complex conductivity spectra. The geometrical factor was obtained numerically, solving the Laplace equation for the electrical potential with considering the geometry of the sandbox and the position of the electrodes. The geometry of the numerical model was the same as the experimental sandbox. Five lines of 40 electrodes were placed at the surface of the model. Two current sources were set at the left and right side of the sandbox. The electrical potential distribution was obtained after running the numerical model (Fig. 12b). The geometrical factor was consequently calculated by the obtained electrical potential, injected current and 

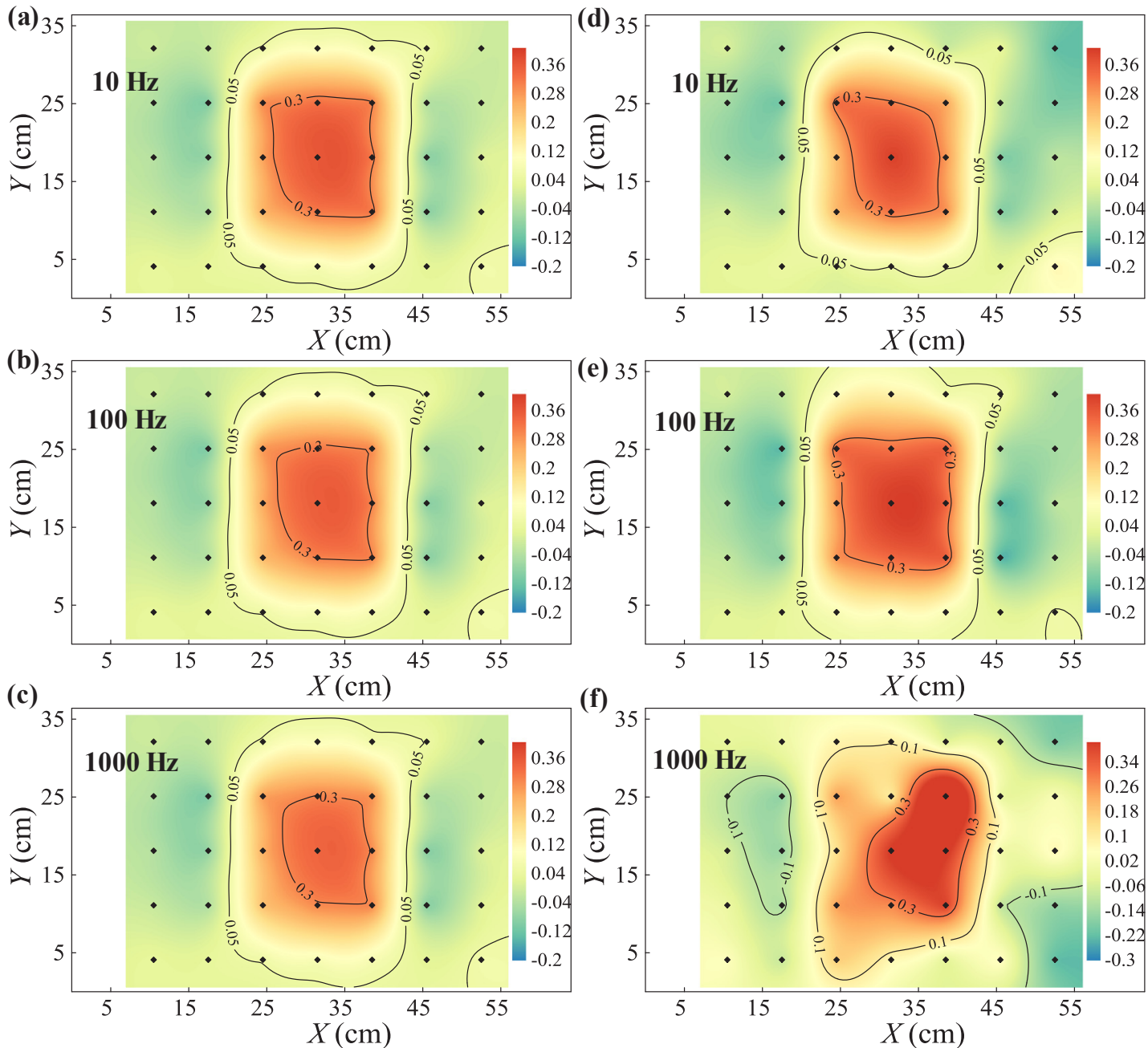

Fig. 15. Oil saturation map estimated from the in-phase conductivity (a), (b), (c) and the quadrature conductivity (d), (e), (f) in the sandbox.

homogeneous resistivity. The obtained geometrical factor was $3.6 \mathrm{~m}^{-1}$.

\subsection{Estimation of the oil saturation and volume}

Fig. 13 displays the spectra of the in-phase and quadrature conductivities in the center of the sandbox before and after contamination. There is an obvious decrease in the magnitude of the complex conductivities after contamination, which is consistent with the results in the column experiments. Since the data collected from the SIP measurements was scattered, the linear interpolation method was employed between adjacent points to map the continuous distribution of the inphase and quadrature conductivities across the whole sandbox (Fig. 14). The contaminated zone is well recognized, indicating that the SIP method is able to characterize the contaminant plume.

Further, we applied Eqs. (2) and (6) to convert the in-phase and quadrature conductivities into oil saturation to obtain the map of oil saturation distribution in the sandbox (Fig. 15). The oil-contaminated zone is revealed particularly well for frequencies 10 and $100 \mathrm{~Hz}$. However, the contaminated area estimated at $1000 \mathrm{~Hz}$ is different, which might be due to the phase error arising from the electromagnetic coupling effect between the cable and the media at the frequencies above $100 \mathrm{~Hz}$ (Pelton et al., 1978; Slater and Lesmes, 2002). This phase error is assumed to be related to the reference resistor and the sample (Lesmes and Frye, 2001). Small-scale measurement, such as laboratory column experiments, may permit the use of higher frequency. However, the measurement in the intermediate-scale equipment (e.g., sandbox) can be inaccurate at higher frequency. The estimated oil saturation is between 0.1 and 0.4 in the contaminated zone. In order to estimate the oil volume, we divided the interest volume into 35 cells with a dimension of $0.07 \mathrm{~m} \times 0.07 \mathrm{~m} \times 0.06 \mathrm{~m}$ for each cell. The oil volume of each cell is obtained by making a product of cell volume, porosity and corresponding oil saturation. The total volume is thus the sum of all 35 cells. Fig. 16 shows the oil volume estimated from the data of in-phase and quadrature conductivities at different frequencies. The result indicates an oil volume between 288.5 and $355 \mathrm{ml}, 67.9-83.5 \%$ of real values. This result is encouraging though the estimated volume is some lower than the true one which is perhaps caused by the bypassing of current flow in the most resistive parts of the sandbox.

The encouraging results from the sandbox experiment strongly suggests that field SIP datasets have the inherent potential for quantifying the hydrocarbon in contaminated sites. Recent field SIP investigations have evidenced the ability of SIP technique for practical problems, with the SIP signatures found to correlate well with the subsurface hydrocarbon concentration (e.g., Flores Orozco et al., 2012) and microbial activity (e.g., Orozco et al., 2013). Thus we believe that the SIP measurement protocol proposed in this paper will be useful for the quantitative investigation in hydrocarbon contaminated sites. Certainly, there are also limitations existing in the application of SIP technique from laboratory scale to field scale. Firstly, extracting the information of interest from detected SIP anomalies, accompanying with the overlapping contributions of hydrology, geology and biochemistry, is still challenging (Kemna, 2012). It is necessary to combine with other constrained datasets, including hydrological, biological and geological information, to discriminate the SIP source mechanisms 

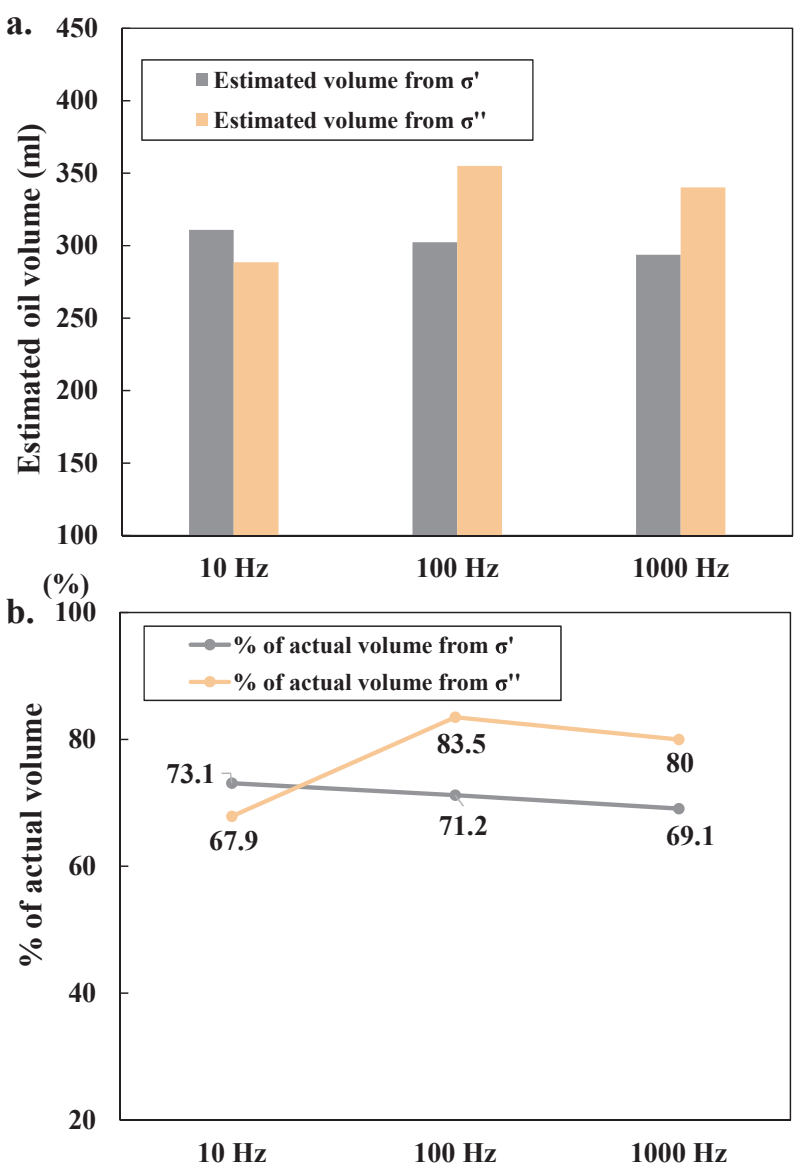

Fig. 16. Estimated oil volume (a) and corresponding percentage of actual volume (b) from the in-phase and quadrature conductivities data at 10, 100 and $1000 \mathrm{~Hz}$.

(Ruggeri et al., 2014; Dailey et al., 2015). Secondly, the data quality can suffer from the electromagnetic coupling effect between the cable and the earth at high frequency for field SIP investigations (Pelton et al., 1978; Lesmes and Frye, 2001). Typically, due to the effects of electromagnetic coupling, the useful frequency range utilized in the field is restricted to $10^{-2}-10^{2} \mathrm{~Hz}$ (Slater and Lesmes, 2002). Solutions to this problem are mostly indirect by removing the inductive coupling component from acquired datasets (Wynn and Zonge, 1975; Routh and Oldenburg, 2001), it is therefore important to develop advanced instruments to directly solve this problem.

\section{Conclusion}

We have performed a series of spectral induced polarization measurements on clayey soils investigating the influence of soil and water properties on the exponents $n$ and $p$ and conducted a sandbox experiment to further explore the availability of the SIP technique in the quantitative characterization of organic contamination.

The complex conductivity spectrum demonstrates that the decrease of water saturation leads to a decrease of magnitude in both in-phase and quadrature conductivities. As the pore water salinity increases, the values of $n$ and $p$ increase slightly when using a linear conductivity model. The value of $n$ shows a weak dependence on the cation exchange capacity (CEC) and specific surface area $\left(S_{s p}\right)$ while the exponent $p$ exhibits a relatively stronger correlation with CEC and $S_{s p}$. The empirical relationship between $n$ and $p$ with $p=n-1$ fits well for the samples with a low CEC. However, with higher CEC (greater than $10 \mathrm{meq} / 100 \mathrm{~g})$, the exponent $p$ becomes extremely high $(\geq 2)$ while the saturation exponent increases very slowly, this relationship $p=n-1$ is therefore limited.

In the sandbox experiment, the SIP measurements are able to accurately map the oil plume and provide an encouraging estimation of oil volume, averagely $70-80 \%$ of true values. For the first time, the SIP method is used for the quantification of oil saturation and volume. This will open up new opportunities for monitoring the oil contamination in field contaminated sites, combining with the development of the data fusion and assimilation and advanced instruments for the SIP method.

\section{Acknowledgements}

This work was financially supported by the National Nature Science Foundation of China grants (No. U1503282 and 41672229). The authors would like to thank the two anonymous referees for their insightful comments and suggestions, which significantly improve the quality of this work.

\section{References}

Aal, G., Slater, L., Atekwana, E., 2006. Induced-polarization measurements on unconsolidated sediments from a site of active hydrocarbon biodegradation. Geophysics 71 (2), H13-H24. http://dx.doi.org/10.1190/1.2187760.

Abdel Aal, G.Z., Atekwana, E.A., 2014. Spectral induced polarization (SIP) response of biodegraded oil in porous media. Geophys. J. Int. 196 (2), 804-817. http://dx.doi. org/10.1093/gji/ggt416.

Aran, D., Maul, A., Masfaraud, J.-F., 2008. A spectrophotometric measurement of soil cation exchange capacity based on cobaltihexamine chloride absorbance. C. R. Geosci. 340 (12), 865-871. http://dx.doi.org/10.1016/j.crte.2008.07.015.

Archie, G.E., 1942. The electrical resistivity log as an aid in determining some reservoir characteristics. Trans. Am. Ind. Min. Metall. Pet. Eng. 146 (01), 54-62. http://dx.doi. org/10.2118/942054-g.

Argaud, M., Giouse, H., Straley, C., Tomanic, J., Winkler, K., 1989. Salinity and saturation effects on shaly sandstone conductivity. SPE 64th Annual Technical Conference and Exhibition. Society of Petroleum Engineers, San Antonio, Texas.

Atekwana, E.A., Atekwana, E.A., 2010. Geophysical signatures of microbial activity at hydrocarbon contaminated sites: a review. Surv. Geophys. 31 (2), 247-283. http:// dx.doi.org/10.1007/s10712-009-9089-8.

Atekwana, E.A., Aal, G.Z.A., 2015. Iron biomineralization controls on geophysical sig natures of hydrocarbon contaminated sediments. J. Earth. Sci. 26 (6), 835-843. http://dx.doi.org/10.1007/s12583-015-0611-2.

Bekri, S., Howard, J., Muller, J., Adler, P.M., 2003. Electrical resistivity index in multiphase flow through porous media. Transp. Porous Med. 51 (1), 41-65. http://dx.doi. org/10.1023/A:1021229106005.

Binley, A., Slater, L.D., Fukes, M., Cassiani, G., 2005. Relationship between spectral induced polarization and hydraulic properties of saturated and unsaturated sandstone. Water Resour. Res. 41 (12), W12417. http://dx.doi.org/10.1029/2005WR004202.

Börner, F., Gruhne, M., Schön, J., 1993. Contamination indications derived from electrical properties in the low frequency range. Geophys. Prospect 41 (1), 83-98. http:// dx.doi.org/10.1111/j.1365-2478.1993.tb00566.x.

Breede, K., Kemna, A., 2012. Spectral induced polarization measurements on variably saturated sand-clay mixtures. Near Surf. Geophys. 10 (6), 479-489. http://dx.doi. org/10.3997/1873-0604.2012048.

Breen, S.J., Carrigan, C.R., LaBrecque, D.J., Detwiler, R.L., 2012. Bench-scale experiments to evaluate electrical resistivity tomography as a monitoring tool for geologic $\mathrm{CO} 2$ sequestration. Int. J. Greenhouse Gas Contl. 9, 484-494. http://dx.doi.org/10.1016/ j.ijggc.2012.04.009.

Chambers, J.E., Loke, M.H., Ogilvy, R.D., Meldrum, P.I., 2004. Noninvasive monitoring of DNAPL migration through a saturated porous medium using electrical impedance tomography. J. Contam. Hydrol. 68 (1), 1-22. http://dx.doi.org/10.1016/S01697722(03)00142-6.

Culligan, K.A., Wildenschild, D., Christensen, B.S.B., Gray, W.G., Rivers, M.L., 2006. Porescale characteristics of multiphase flow in porous media: a comparison of air-water and oil-water experiments. Adv. Water Resour. 29 (2), 227-238. http://dx.doi.org/ 10.1016/j.advwatres.2005.03.021.

Dailey, D., et al., 2015. Geophysical, remote sensing, GIS, and isotopic applications for a better understanding of the structural controls on groundwater flow in the Mojave DesertCalifornia. J. Hydrol. Reg. Stud. 3, 211-232. http://dx.doi.org/10.1016/j.ejrh. 2014.12.002.

Flores Orozco, A., et al., 2012. Delineation of subsurface hydrocarbon contamination at a former hydrogenation plant using spectral induced polarization imaging. J. Contam. Hydrol. 136-137, 131-144. http://dx.doi.org/10.1016/j.jconhyd.2012.06.00.

Hördt, A., et al., 2016. The dependence of induced polarization on fluid salinity and $\mathrm{pH}$, studied with an extended model of membrane polarization. J. Appl. Geophys. 135, 408-417. http://dx.doi.org/10.1016/j.jappgeo.2016.02.007.

Halihan, T., Sefa, V., Sale, T., Lyverse, M., 2017. Mechanism for detecting NAPL using electrical resistivity imaging. J. Contam. Hydrol. 205, 57-69. http://dx.doi.org/10. 1016/j.jconhyd.2017.08.007.

Hearst, J., Nelson, P.H., Paillet, F.L., 2000. Well Logging for Physical Properties: A Handbook for Geophysicists, Geologists and Engineers. John Wiley and Sons Ltd, West Sussex, England. 
Heenan, J., et al., 2013. Sensitivity of the spectral induced polarization method to microbial enhanced oil recovery processes. Geophysics 78 (5), E261-E269. http://dx. doi.org/10.1190/geo2013-0085.1.

Keller, G.V., Frischknecht, F.C., 1966. Electrical Methods in Geophysical Prospecting. Pergamon Press Inc., Oxford.

Kemna, A., 2012. An overview of the spectral induced polarization method for nearsurface applications. Near Surf. Geophys. 10 (6), 453-468. http://dx.doi.org/10. 3997/1873-0604.2012027.

Koch, K., Kemna, A., Irving, J., Holliger, K., 2011. Impact of changes in grain size and pore space on the hydraulic conductivity and spectral induced polarization response of sand. Hydrol. Earth Syst. Sc. 15 (6), 1785-1794. http://dx.doi.org/10.5194/hess15-1785-2011.

Kumar, M., et al., 2010. Mapping 3D pore scale fluid distributions: How rock resistivity is influenced by wettability and saturation history. Petrophysics 51 (02), 102-117.

Leroy, P., Revil, A., Kemna, A., Cosenza, P., Ghorbani, A., 2008. Complex conductivity of water-saturated packs of glass beads. J. Colloid. Interf. Sci. 321 (1), 103-117. http:// dx.doi.org/10.1016/j.jcis.2007.12.031.

Leroy, P., Revil, A., 2009. A mechanistic model for the spectral induced polarization of clay materials. J. Geophys. Res-Sol. Ea. 114 (B10). http://dx.doi.org/10.1029/ 2008JB006114.

Lesmes, D.P., Frye, K.M., 2001. Influence of pore fluid chemistry on the complex conductivity and induced polarization responses of Berea sandstone. J. Geophys. Res-Sol. Ea. 106 (B3), 4079-4090. http://dx.doi.org/10.1029/2000JB900392.

Longeron, D.G., 1990. Laboratory measurements of capillary and electrical properties of rock samples at reservoir conditions: Effect of some parameters. SCA ConferenceSCA9023.

Maineult, A., Revil, A., Camerlynck, C., Florsch, N., Titov, K., 2017. Upscaling of spectral induced polarization response using random tube networks. Geophys. J. Int. 209 (2), 948-960. http://dx.doi.org/10.1093/gji/ggx066.

Mao, D., et al., 2015. Resistivity and self-potential tomography applied to groundwater remediation and contaminant plumes: Sandbox and field experiments. J. Hydrol. 530, 1-14. http://dx.doi.org/10.1016/j.jhydrol.2015.09.031.

Martinez, F., Batzle, M., Revil, A., 2012. Influence of temperature on seismic velocities and complex conductivity of heavy oil-bearing sands. Geophysics 77 (3), WA19-WA34. http://dx.doi.org/10.1190/geo2011-0433.1.

Mercer, J.W., Cohen, R.M., 1990. A review of immiscible fluids in the subsurface: properties, models, characterization and remediation. J. Contam. Hydrol. 6 (2), 107-163. http://dx.doi.org/10.1016/0169-7722(90)90043-G.

Nasralla, R.A., Bataweel, M.A., Nasr-El-Din, H.A., 2013. Investigation of wettability alteration and oil-recovery improvement by low-salinity water in sandstone rock. J. Can. Petrol. Technol. 52 (02), 144-154. http://dx.doi.org/10.2118/146322-PA.

Newell, C.J., Acree, S.D., Ross, R.R., Huling, S.G., 1991. Light Nonaqueous Phase Liquids. U.S. Environmental Protection Agency Ground Water Issue Paper EPA/540/S-95/ 500. Ada, Oklahoma: R.S. Kerr Environmental Research Laboratory.

Niu, Q., Revil, A., Saidian, M., 2016. Salinity dependence of the complex surface conductivity of the Portland sandstone. Geophysics 81 (2), D125-D140. http://dx.doi. org/10.1190/GEO2015-0426.1.

Orozco, A.F., Williams, K.H., Kemna, A., 2013. Time-lapse spectral induced polarization imaging of stimulated uranium bioremediation. Near Surf. Geophys. 11 (5), 531-544. http://dx.doi.org/10.3997/1873-0604.2013020.

Pelton, W., Ward, S., Hallof, P., Sill, W., Nelson, P., 1978. Mineral discrimination and removal of inductive coupling with multifrequency IP. Geophysics 43 (3), 588-609. http://dx.doi.org/10.1190/1.1440839.

Revil, A., Cathles, L.M., Losh, S., Nunn, J.A., 1998. Electrical conductivity in shaly sands with geophysical applications. J. Geophys. Res.-Sol. Ea. 103 (B10), 23925-23936. http://dx.doi.org/10.1029/98JB02125.

Revil, A., Florsch, N., 2010. Determination of permeability from spectral induced polarization in granular media. Geophys. J. Int. 181 (3), 1480-1498. http://dx.doi.org/10. 1111/j.1365-246X.2010.04573.x.

Revil, A., Schmutz, M., Batzle, M., 2011. Influence of oil wettability upon spectral induced polarization of oil-bearing sands. Geophysics 76 (5), A31-A36. http://dx.doi. org/10.1190/geo2011-0006.1.

Revil, A., Skold, M., 2011. Salinity dependence of spectral induced polarization in sands and sandstones. Geophys. J. Int. 187 (2), 813-824. http://dx.doi.org/10.1111/j. 1365-246X.2011.05181.x.

Revil, A., Atekwana, E., Zhang, C., Jardani, A., Smith, S., 2012a. A new model for the spectral induced polarization signature of bacterial growth in porous media. Water Resour. Res. 48, W09545. http://dx.doi.org/10.1029/2012WR011965.

Revil, A., Koch, K., Holliger, K., 2012b. Is it the grain size or the characteristic pore size that controls the induced polarization relaxation time of clean sands and sandstones? Water Resour. Res. 48, W05602. http://dx.doi.org/10.1029/2011WR011561.

Revil, A., 2013a. On charge accumulation in heterogeneous porous rocks under the influence of an external electric field. Geophysics 78 (4), D271-D291. http://dx.doi. org/10.1190/geo2012-0503.1.

Revil, A., 2013b. Effective conductivity and permittivity of unsaturated porous materials in the frequency range $1 \mathrm{mHz}-1 \mathrm{GHz}$. Water Resour. Res. 49 (1), 306-327. http://dx. doi.org/10.1029/2012WR012700.

Revil, A., et al., 2013. Low-frequency complex conductivity of sandy and clayey materials. J. Colloid Interf. Sci. 398, 193-209. http://dx.doi.org/10.1016/j.jcis.2013.01.015.

Revil, A., et al., 2017. Complex conductivity of soils. Water Resour. Res. 53, 7121-7147. http://dx.doi.org/10.1002/2017WR020655.
Routh, P.S., Oldenburg, D.W., 2001. Electromagnetic coupling in frequency-domain in duced polarization data: a method for removal. Geophys. J. Int. 145 (1), 59-76. http://dx.doi.org/10.1111/j.1365-246X.2001.00384.x.

Rubin, Y., Hubbard, S.S., 2005. Hydrogeophysics, 50. Springer Science \& Business Media, Dordrecht, the Netherlands.

Ruggeri, P., Gloaguen, E., Lefebvre, R., Irving, J., Holliger, K., 2014. Integration of hydrological and geophysical data beyond the local scale: Application of Bayesian sequential simulation to field data from the Saint-Lambert-de-Lauzon site, Québec, Canada. J. Hydrol. 514, 271-280. http://dx.doi.org/10.1016/j.jhydrol.2014.04.031.

Sarma, V.J., Rao, V.B., 1962. Variation of electrical resistivity of river sands, calcite, and quartz powders with water content. Geophysics 27 (4), 470-479. http://dx.doi.org/ $10.1190 / 1.1439048$.

Schmutz, M., et al., 2010. Influence of oil saturation upon spectral induced polarization of oil-bearing sands. Geophys. J. Int. 183 (1), 211-224. http://dx.doi.org/10.1111/j. 1365-246X.2010.04751.x.

Schmutz, M., Blondel, A., Revil, A., 2012. Saturation dependence of the quadrature conductivity of oil-bearing sands. Geophys. Res. Lett. 39 (3), L03402. http://dx.doi. org/10.1029/2011GL050474.

Schwartz, N., Furman, A., 2012. Spectral induced polarization signature of soil contaminated by organic pollutant: Experiment and modeling. J. Geophys. Res.-Sol. Ea. 117 (B10), B10203. http://dx.doi.org/10.1029/2012JB009543.

Schwartz, N., Huisman, J.A., Furman, A., 2012. The effect of NAPL on the electrical properties of unsaturated porous media. Geophys. J. Int. 188 (3), 1007-1011. http:// dx.doi.org/10.1111/j.1365-246X.2011.05332.x.

Schwarz, G., 1962. A theory of the low-frequency dielectric dispersion of colloidal particles in elctrolyte solution 1,2. J. Phys. Chem. 66 (12), 2636-2642. http://dx.doi. org/10.1021/j100818a067.

Slater, L., Lesmes, D.P., 2002. Electrical-hydraulic relationships observed for unconsolidated sediments. Water Resour. Res. 38 (10), 1213. http://dx.doi.org/10. 1029/2001WR001075.

Slater, L., Glaser, D., 2003. Controls on induced polarization in sandy unconsolidated sediments and application to aquifer characterization. Geophysics 68 (5), 1547-1558. http://dx.doi.org/10.1190/1.1620628.

Sondenâ, E., Bratteli, F., Norman, H., Killtveit, K., 1990. The effect of reservoir conditions on saturation exponent and capillary pressure curve for water-wet samples. Advances in Core Evaluation I, Ed. Worthington.

Titov, K., Komarov, V., Tarasov, V., Levitski, A., 2002. Theoretical and experimental study of time domain-induced polarization in water-saturated sands. J. Appl. Geophys. 50 (4), 417-433. http://dx.doi.org/10.1016/S0926-9851(02)00168-4.

Titov, K., Kemna, A., Tarasov, A., Vereecken, H., 2004. Induced polarization of unsaturated sands determined through time domain measurements. Vadose Zone J. 3, 1160-1168. http://dx.doi.org/10.2136/vzj2004.1160.

Toumelin, E., Torres-Verdin, C., 2005. Influence of oil saturation and wettability on rock resistivity measurements: a uniform pore-scale approach. In: SPWLA 46th Annual Logging Symposium, Society of Petrophysicists and Well-Log Analysts, New Orleans, Louisiana.

Ulrich, C., Slater, L., 2004. Induced polarization measurements on unsaturated, unconsolidated sands. Geophysics 69 (3), 762-771. http://dx.doi.org/10.1190/1. 1759462.

Vanhala, H., Soininen, H., 1995. Laboratory technique for measurement of spectral in duced polarization response of soil sampies. Geophys. Prospect. 43 (5), 655-676. http://dx.doi.org/10.1111/j.1365-2478.1995.tb00273.x.

Vanhala, H., 1997. Mapping oil-contaminated sand and till with the spectral induced polarization (SIP) method. Geophys. Prospect. 45 (2), 303-326. http://dx.doi.org/10. 1046/j.1365-2478.1997.00338.x.

Vargaftik, N.B., Volkov, B.N., Voljak, L.D., 1983. International tables of the surface tension of water. J. Phys. Chem. Ref. Data 12 (3), 817-820. http://dx.doi.org/10.1063/ 1.555688 .

Vaudelet, P., Revil, A., Schmutz, M., Franceschi, M., Bégassat, P., 2011. Induced polarization signatures of cations exhibiting differential sorption behaviors in saturated sands. Water Resour. Res. 47, W02526. http://dx.doi.org/10.1029/2010WR009310.

Vinegar, H., Waxman, M., 1984. Induced polarization of shaly sands. Geophysics 49 (8), 1267-1287. http://dx.doi.org/10.1190/1.1441755.

Wang, Y., Sharma, M.M., 1988. A network model for the resistivity behavior of partially saturated rocks, SPWLA 29th Annual Logging Symposium. Society of Petrophysicists and Well-Log Analysts, San Antonio, Texas.

Waxman, M.H., Smits, L., 1968. Electrical conductivities in oil-bearing shaly sands. Soc. Petrol. Eng. J. 8 (02), 107-122. http://dx.doi.org/10.2118/1863-A.

Weller, A., Slater, L., 2012. Salinity dependence of complex conductivity of unconsolidated and consolidated materials: Comparisons with electrical double layer models. Geophysics 77 (5), D185-D198. http://dx.doi.org/10.1190/geo20120030.1 .

Wynn, J., Zonge, K., 1975. EM coupling, its intrinsic value, its removal and the cultural coupling problem. Geophysics 40 (5), 831-850. http://dx.doi.org/10.1190/1. 1440571.

Zeppieri, S., Rodríguez, J., López de Ramos, A.L., 2001. Interfacial tension of Alkane + water systems. J. Chem. Eng. Data 46 (5), 1086-1088. http://dx.doi.org/10.1021/ je000245r.

Zimmermann, E., et al., 2008. A high-accuracy impedance spectrometer for measuring sediments with low polarizability. Meas. Sci. Technol. 19 (10), 105603. http://dx. doi.org/10.1088/0957-0233/19/10/105603. 